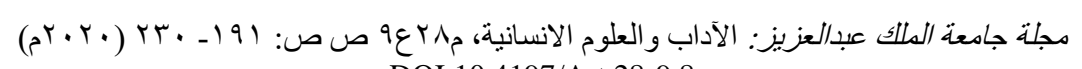

DOI:10.4197/Art.28-9.8

\title{
أدوات الإتصال والتفاعل بالثبكات الاجتماعية كمنتج وعملية دراسة تحليلية على الصفحات الإخبارية أثناء الأحداث الهامة
}

\author{
د. آلاء ماهر خفاجة \\ دكتوراه فى الاعلام من قسم الاعلام \\ كلية الآداب-جامعة الدنيا \\ Dr_alaamaher86@yahoo.com
}

مستخلص.تتبع أهمية هذه الدراسة من أنها من الدراسات التى تحاول فهم كافة العناصر التفاعلية التى تحويها

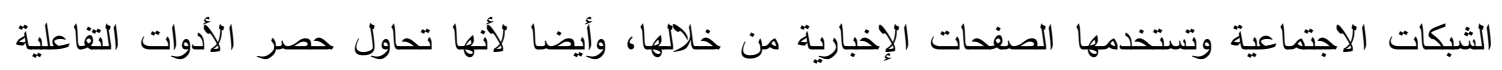

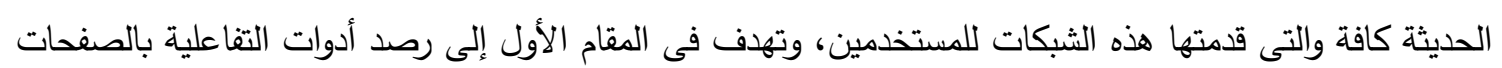

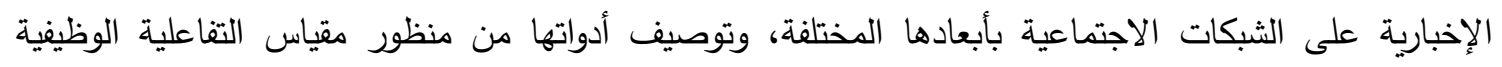

$$
\text { ومعرفة مدى استخدام الجمهور العربي لهذه الأدوات أثناء الأحداث الهامة. }
$$

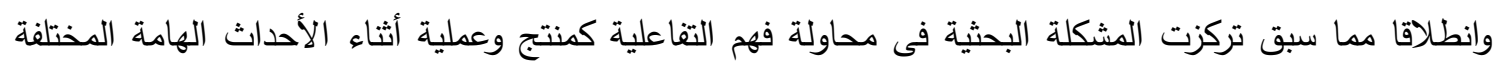

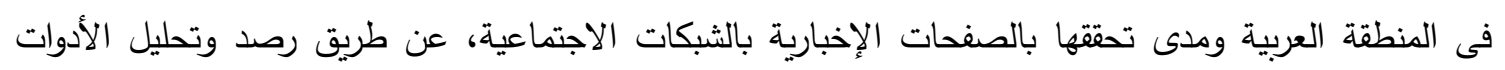

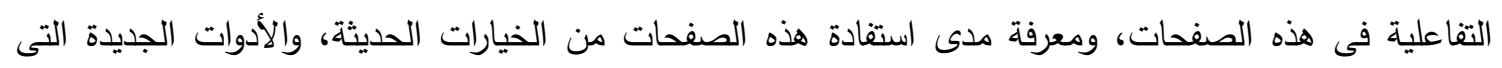

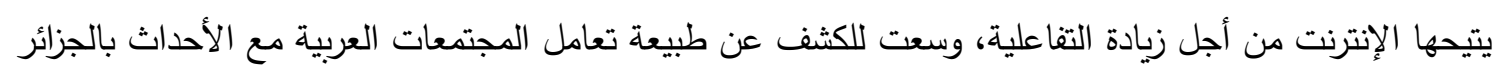

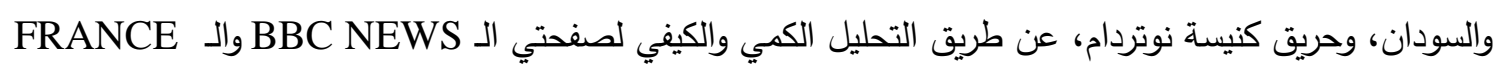

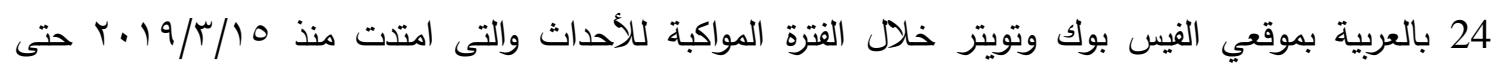

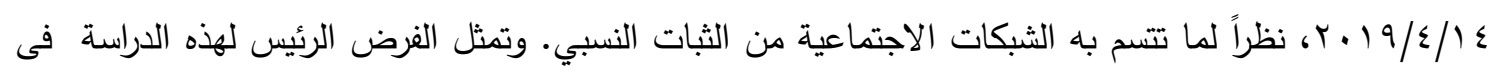

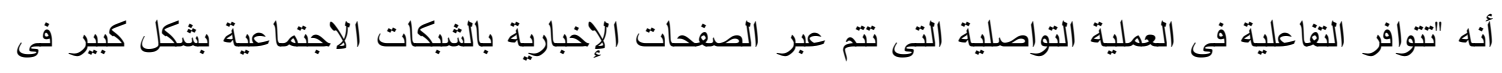

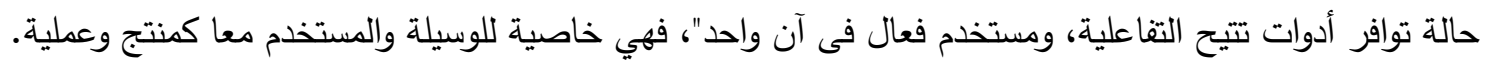

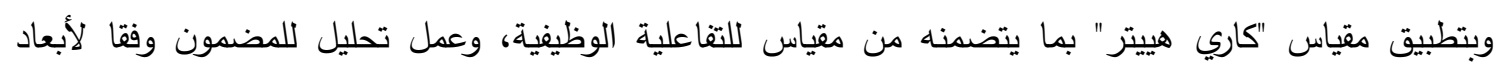

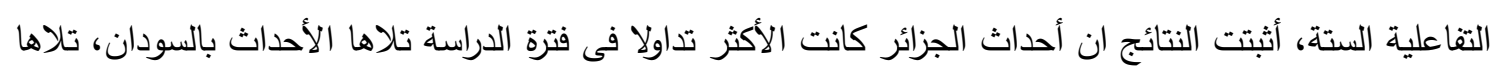

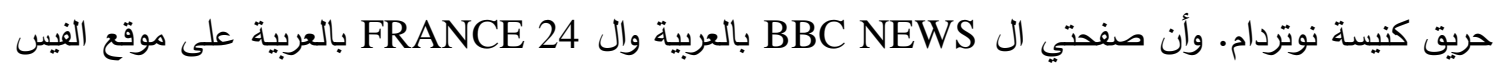

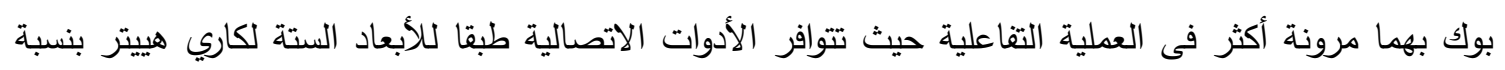


عالية مقارنة بالصفتين بموقع التويتر وإن كان الفارق ضئيلاً، واتضحت التفاعلية كمنتج فى توافر الأدوات

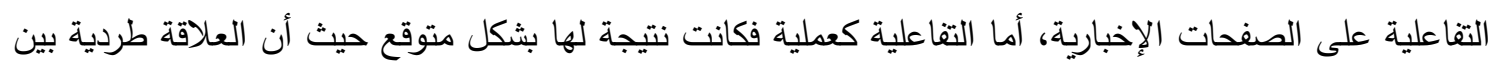
توفر المنتج وإتاحة استعماله.

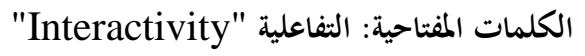

الصفحات الإخبارية "News pages"

"Social networks" الشبكات الاجتماعية الإنانة

"Jennifer Stromer" تتمحور حول التفاعلية كعملية حيث ركزت على التى التفاعل الإنساني إلا أنه فى الآونة الأخيرة يحاول

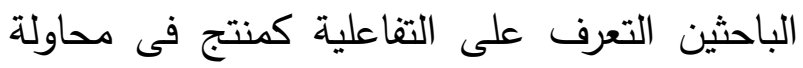
لرصد تفاعل المستخدم مع التكنولوجيا(؟). وينقسم هذا البحث إلى شطرين: الأول يحاول فهم

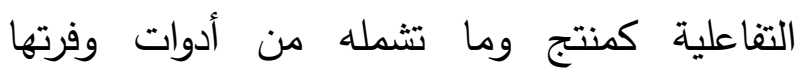
الشبكات الاجتماعية ليستخدمها الأشخاص أثناء تواجدهم على الصفحات الإخبارية المتعددة بالشبكات الاجتماعية، وسوف تطبق الباحثة أبعاد

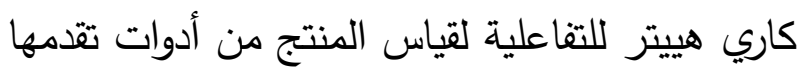
هذه المواقع كيفيا، والثاني محاولة لفهم العملية التفاعلية التى يقوم بها الأشخاص كعملية افتراضية ممتدة عن العالم الواقعي وذلك بالتحليل الكمي لنفس لنس الأبعاد.

وتحاول الباحثة بهذه الدراسة معرفة تعامل المجتمع معادع المصري وتفاعله مع الصفحات الاخبارية بالثبكات

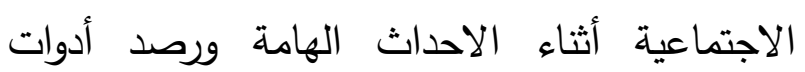

2 Jennifer Stromer-Galley (2004) Interactivity-asProduct and Interactivity-as-Process, The Information Society, 20:5, 391-394, DOI: 10.1080/01972240490508081.

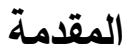

يتميز الإعلام الجديد على شبكة الويب بعدة سمات وخصائص اتصالية وفقا لما هو جديد من تطور الإنيل تكنولوجي فى عالم الإنترنت، ومن أهم هذه السمات

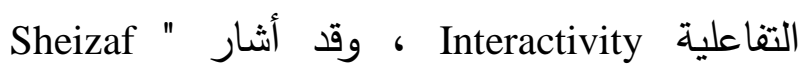

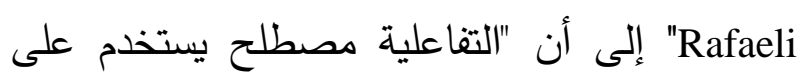
نطاق واسع، لكنه مفهوم غير محدد التعريف، ولكن عند التفكير فى عملية الاتصال فإن التفاعلية مصطلح ذو صلاحية كبيرة فى الاستخدام، ولكن بإجماع ضئيل على المعنى، وفى الآونة الأخيرة

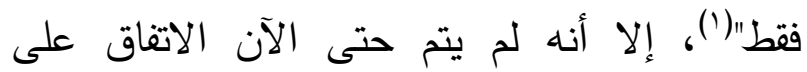
تعريف واضح ومحدد للتفاعلية. ويمكن أن نقول بأن هناك اختلافاً فيما إذا كانت

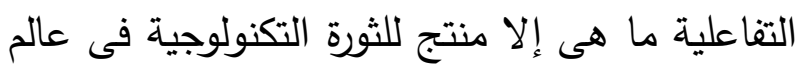
الإعلام الجديد، أو أنها مجرد عمليه ممتدة من العالم لماليه

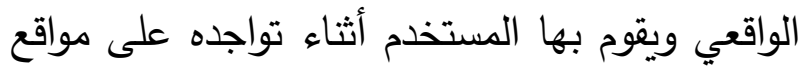
الويب المختلفة بأشكالها وتطبيقاتها الحديثة، أم أنها خيار يجمع ما بين النوعين، يثيث أشارت

${ }^{1}$ Jensen, J.F. " Interactivity : Tracking a new concepts in media and communication studies ". Nordicom Review, vol.(19),no.(1),November 2003 at :http://www.nordicom.gu.se/common/publ-pdf/38jensen.pdf. pp. 185. 


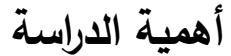

تتبع أهمية هذه الدراسة من أنها من الدراسات التى تحاول فهم كافة العناصر التفاعلية التى تحويها الثبكات الاجتماعية وتستخدها الصفحات الإخبارية

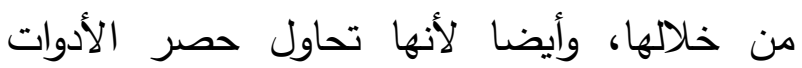
التفاعلية الحديثة كافة والتى قدمتها هذه الشبكات

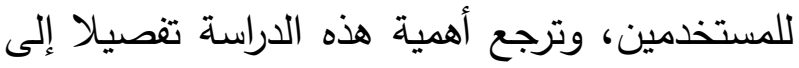

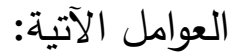

1. قلة الدراسات التي تناولت التفاعلية الصفحات

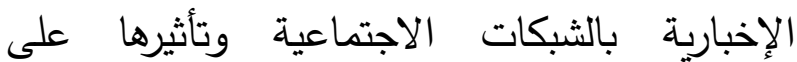
المجتمع المصري؛ فمازالت هذه الفئة بحاجة إلى العديد من الدراسات المستفيضة التى تبحث فى علاقاتها بالتطور التكنولوجي فى مجال الإعلام والاتصال والمعلومات. r. الحاجة إلى معرفة موقع المجتمع المصري من كل هذا الزخم حول الشبكات الاجتماعية وتقصى الأخبار والمعلومات والتفاعل افتراضيا. r. تتضح أهمية الدراسة أيضا من خلال التحليل الكمي والكيفي معاً للصفحات عينة الدراسة.

\section{مصطلحات الدراسة}

1- التفاعلية Interactivity: عرفها أحد الباحثين بأنها من أهم سمات المجتمع المعلوماتي ، وتعني قدرة مستقبل الاتصال علي التعامل مع المشتركين الآخرين وتبادل ردود الأفعال المستمر لمعلومات

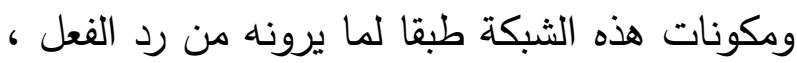
ولهذا تتميز التفاعلية بالتشبيك، بمعني الربط الكامل
الاتصال والتفاعل وفقا للابعاد السته كما صنفتها "هييتر" فى محاولة للوقوف على فاعليتها وأهميتها. مثكلة الاراسة

لم تحدث الإنترنت فى دول العالم المختلفة نفس التأثير الذي أحدثته في المنطقة العربية؛ فالأمر فى لـى لإنى الدول العربية يتوقف على عوامل ومتغيرات أخرى تختلف فى طبيعتها، أهمها العادات والتقاليد والثقافة المجتمعية والحالة الاقتصادية والاجتماعية والسياسية

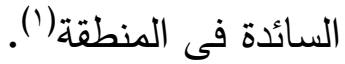
وفى ضوء الإطار النظري للدراسة ونتائج الدراسات السابقة التى سيتم عرضها والتى لاحظنا قصورها فى تناول التفاعلية كمنتج وعملية؛ تتمحور إشكالية هذه الدراسة فى محاولة فهم التفاعلية كمنتج و عملية أثناء الأحداث الهامة المختلفة فى المنطقة العربية. ويمكن تلخيص مشكلة هذه الدراسة فى "التعرف على مدى تحقق التفاعلية كمنتج وعملية بالصفحات الإخبارية بالثبكات الاجتماعية، عن طريق رصد وتحليل الأدوات التفاعلية فى هذه الصفحات، ومعرفة مدى الاستفادة من الخيارات الحديثة، والأدوات الجديدة التى يتيحها الإنترنت من أجل زيادة التفاعلية ". حيث أنه لا توجد دراسات سابقة تناولت التفاعلية بإعتبارها منتج وعملية فى آن واحد.

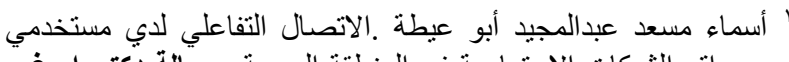

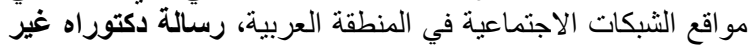

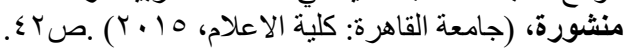


وقدم كلٌ من بويد وإليسون (V. . . r) تعريف مواقع الشبكات الاجتماعية بأنها "هي الخدمات على شبكة الانترنت التي تسمح ببناء ملف شخصي عام أو شبه عام ضدن نظام محدود وبيان قائمة بالمستخدمين الآخرين الذين

يشاركونهم فى الاتصال، وعرض قائمة بالاتصالات الخاصة بهم، وبالآخرين داخل نفس النظام(؛). وتعرفها الباحثة إجرائيا: هى مواقع إلكترونية اجتماعية تفاعلية تسمح للمستخدمين بمشاركة اهتماماتهم، ويمكن الولوج اليها بكل سهولة، وهى مناسبة لكل الفئات والاعمار ع - الصفحات الإخبارية: هى صفحات مخصصة لإذاعة الأخبار والأشكال الصحفية المختلفة على شبكات التواصل الاجتماعي تتبع هيئة إخبارية معروفة، سواء قناة إخبارية، جريدة، وكالة أنباء، مستخدمة نظام الكابل الرقمي المتصل بالكمبيوتر، وهى تقدم العديد من الخدمات مثل الروابط التشعبية المتصلة بين الصفحات الإخبارية والموقع الإلكتروني (0). وتعرفها الباحثة إجرائيا: هى صفحات إخبارية تابعة لهيئة إخبارية وتبث على شبكات التواصل الاجتماعي.

\footnotetext{
${ }^{(4)}$ Boyd,D.M.,\&Ellison,N.B(2007).SocialNetworkSites: Definition,History,andScholarship.Journal of Computer-Mediated Communication,13(1),210230.

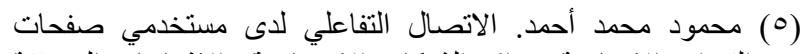

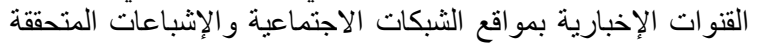

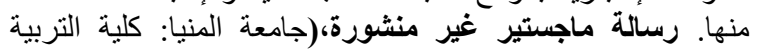

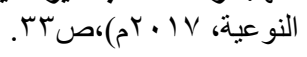

بين جميع مستخدمي الشبكة فى إطار الصحافة الإلكترونية (') وتعرفها الباحثة إجرائيا: هي الأدوات المتاحة على مواقع الإنترنت الحديثة، من أجل جعل المستخدم متلقٍ ومرسل ومشارك للمعلومات. r- الشبكات الاجتماعية:Social Networks: r- مصطلح يطلق على مجموعة من المواقع على شبكة الإنترنت، تتيح التواصل بين الأفراد فى بيئة مجتمع افتراضي، يجمعهم الانتماء لبلد أو مدرسة أو لإلهرئ فئة معينة فى نظام عالمي لنقل المعلومات، ويعرفها نقلا $\quad$ David Ingenito,(2010) Wellman,(1997) بأنها "مجموعة من الأشخاص أو المنظمات أو الكيانات الاجتماعية الأخرى، مرتبطة بواسطة مجموعة من العلاقات ذات مغزى اجتماعيا، عندما تربط شبكة من الإنترنت بين الناس، فهذه هى الثبكات الاجتماعية"(r).

وجاء الاجتماعية networking service خدمة إلكترونية تسمح للمستخدمين بإنشاء وتتظيم ملفات شخصية لهم كما تسمح لهم بالتواصل مع

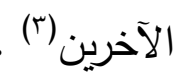

(1) محمد منير حجاب . الموسوعة الاعلامية ،طا( القاهرة: دار الفجر

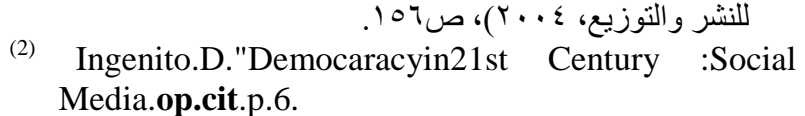

${ }^{(3)}$ Joan M. Reitz. Online Dictionary for Library and Information 1 Science.retrieved from http://www.abc-clio.com/ODLIS/searchODLIS.aspx on April 21, 2015. 
r. كيف قدمت الصفحات الإخبارية بالثبكات الاجتماعية الأدوات التى تحقق بعد الاستجابة للمستخدم على شبكة الإنترنت؟ ـ. كيف قدمت الصفحات الإخبارية بالثبكات الاجتماعية الأدوات التى تحقق بعد تسهيل الاتصال الشخصي على شبكة الإنترنت؟ 0. كيف قدمت الصفحات الإخبارية بالثبكات الاجتماعية الأدوات التى تحقق بعد سهولة إضافة المعلومات على شبكة الإنترنت؟ 7. كيف قدمت الصفحات الإخبارية بالشبكات الاجتماعية الأدوات التى تحقق بعد سهولة إضافة

المعلومات على شبكة الإنترنت؟ V. ما حجم استخدام الجمهور لكل الأدوات السابقة (بشكل كمي)

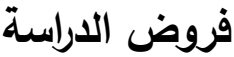

يتمثل الفرض الرئيس لهذه الدراسة فى الآتى: تتوافر التفاعلية فى العملية التواصلية التى تتم عبر الصفحات الإخبارية بالشبكات الاجتماعية بشكل كبير فى حالة توافر أدوات تتيح التفاعلية، ومستخدم فعال فى آن واحد"، فهي خاصية للوسيلة والمستخدم معا كمنتج وعملية، وتفرع منه الفرضان الآتيان: - توجد علاقة ارتباطية ذات دلالة إحصائية بين التفاعلية كمنتج والتفاعلية كعلية بالصفحات الإخبارية بالثبكات الاجتماعية. - توجد علاقة ارتباطية ذات دلالة إحصائية بين كثافة الأخبار والمعلومات المقدمة على الصفحات

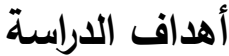

تمثل الهدف الرئيسي لهذه الدراسة فى سعيها إلى

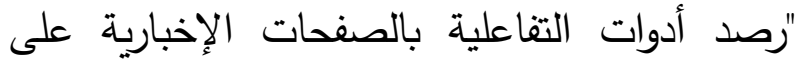
الثبكات الاجتماعية بأبعادها المختلفة، وتوصيف بالفياتها أدواتها من منظور مقياس التفاعلية الوظيفية ومعرفة مدى استخدام الجمهور المصري لهذه الأدوات أثناء

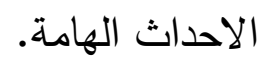
أما الأهداف الفرعية لهذه الدراسة فانقسمت إلى الى التعرف على أبعاد التفاعلية بالصفحات الإخبارية بالشبكات الاجتماعية عينة الدراسة، والتعرف على آليات وأدوات التفاعلية التى توظفها الصفحات الإخبارية بالثبكات الاجتماعية، والتعرف على كيفية توظيف الصفحات الإخبارية بالثبكات الاجتماعية

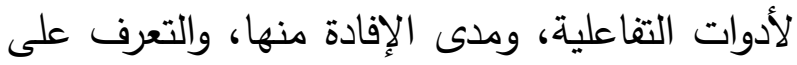
أكثر الادوات استخداما من قبل الجمهور المصري ومستوى التفاعلية لديهم.

\section{تساؤلات الاراسة}

نبعت الأسئلة الخاصة بالدراسة التحليلية، من أبعاد هيتر الستة للتفاعلية وتمثلت فى الآتى:1. كيف قدمت الصفحات الإخبارية بالثبكات الاجتماعية أدوات تفاعلية تخدم بعد تعدد الخيارات

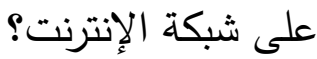
Y. كيف قدمت الصفحات الإخبارية بالشبكات

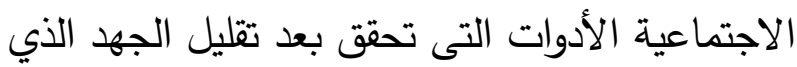
يبذله المستخدم على شبكة الانترنت؟ 
للتفاعلية- باعتبار "هييتر" من قدمت أبعاد التفاعلية بنوع من الإلمام والشمول- للوقوف وحصر كل الأدوات المقدمة عليها كل حسب البعد الذى يمكن تصنيفها من خلاله، وهى: (1) تعدد الخيارات

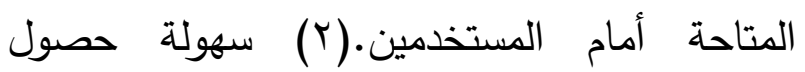
المستخدم على المعلومات.(ب) الاستجابة للمستخدم.(ع) سهولة الاتصال الشخصي.(0) سهولة إضافة المعلومات من قبل المستخدم.(T) مراقبة نظام المستخدم.

الإخبارية بالشبكات الاجتماعية وكثافة التفاعل مع الأدوات التفاعلية المتاحة. الإطار النظري للاراسة في ضوء نتائج الدراسات السابقة، وفى ضوء دراسات أخرى رصدت أبعاد التفاعلية الست لـكاري هييتر" قامت الباحثة بتوظيف "أبعاد التفاعلية" لـ"كاري هييتر" ولجأت فى دراستها التحليلية إلى تصنيف وشرح أدوات الاتصال فى صفحات المواقع الإخبارية بالثبكات الاجتماعية، بناء على الأبعاد الستة وفي ضوء أبعاد "كارى هييتر" الستة للتفاعلية حاولت الباحثة وضع نموذج معادلة كالآتى:

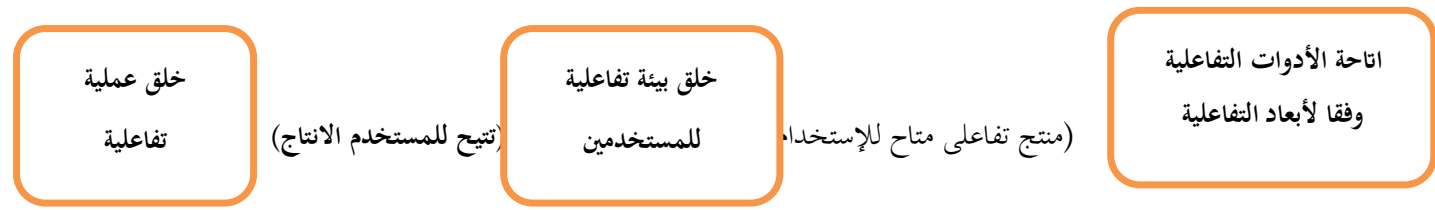

عربية، ومعرفة مدى استخدام هذه الصحف لشبكات التواصل الاجتماعي هن جانب، وتطبيقات الجيل الثاني من الويب من جانب آخر، مستخدمة المنهج الوصفي، وقد اثبت التحليل الميداني للدراسة ما يلي: - - هناك علاقة بين الصحف الإلكترونية العربية والشبكات، واستخدام خصائصها، ولكن دون اهتمام كاف. كان الفيس بوك وتويتر • - جميع الصحف تتيح طباعة المقال، إضافة تعليق، المشاركة على الثبكات.

\section{الاراسات السابقة}

قسمت الباحثة الأدبيات العلمية السابقة التي أجريت في نفس مجال البحث إلى محورين: أ. المحور الأول: دراسات تناولت التفاعلية وعلاقتها بالثبكات الاجتماعية والمواقع الإخبارية والمواقع الحديثة بشكل عام ومنها

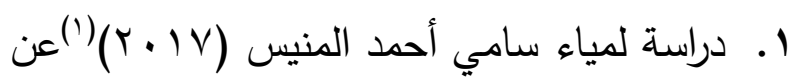
استخدام شبكات التواصل الاجتماعي وانعكاساتها على الصحف الإلكترونية العربية، حاولت هذه الدراسة قياس عينة من الصحف في خمس دول

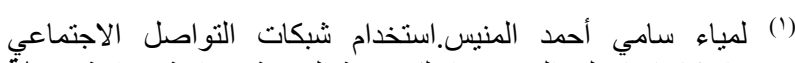

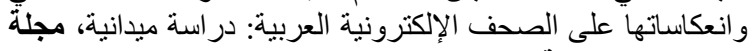

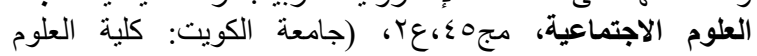
الاجتماعية، V V V V). 
التعرف على أشكال التفاعلية لدى مستخدمي شبكات التواصل الاجتماعي من الثباب العربي، من خلال معرفة عاداتهم فى استخدام هذه الشبكات، ومدى تفاعلهم مع المحتويات والمستخدمين الآخرين. واعتمدت منهج المسح الوصفي لعينة من الثباب المستخدمين لأشهر شبكات التواصل الاجتماعي في الوطن العربي، ومن أهم النتائج التي خلصت اليها

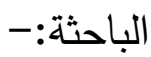

- - استفاد الشباب العربي(عينة الدراسة) مما تتحه شبكات التواصل الاجتماعي من أشكال التفاعلية وأبرزها: البحث عن المحتويات والمضامين، الفعل أو رجع الصدى والتواصل مع الآخرين، المشاركة بالنشر ، وكذا اقتراح الموضوعات النقاشية. - أكدت الدراسة صحة الافتراض الذي انطلقت منه:" تتوافر التفاعلية فى العملية التواصلية التي تتم عبر الوسائط بشكل كبير فى وجود وسيلة تتيح التفاعلية، ومستخدم فعال فى آن واحد"، فهي خاصية للوسيلة والمستخدم معا. - اقترحت الدراسة مصطلحا جديدا فى مجال وسائل الاتصال والتواصل الجديدة وهو" القبيلة أو القبائل الإكترونية" مقابل" المجتمع أو المجتمعات الإلكترونية أو الافتراضية".

ع. دراسة أسماء مسعد عبد المجيد أبو عيطة

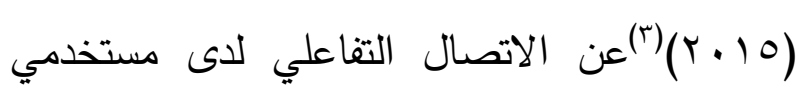

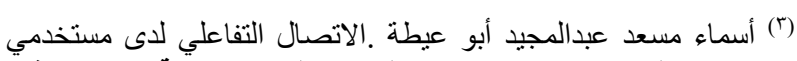

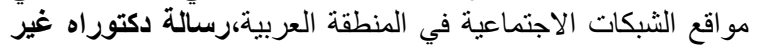

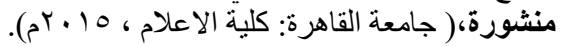

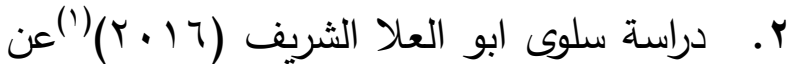
أساليب تحقيق التفاعلية فى تصميم المواقع الإلكترونية السياحية الرسمية، سعت هذه الدراسة الى رصد وتحليل واقع استخدام أساليب التفاعلية في تصميم المواقع الإلكترونية للمؤسسات السياحية الرسمية في مصر ودبي، ومدى استفادة هذه المواقع من الخيارات الحديثة، والوسائل الجديدة التي يتحها الإنترنت من أجل زيادة التفاعلية. وتمثل الهدف الرئيسي لهذه الدراسة في "رصد مدى استخدام أساليب التفاعلية في تصميم المواقع الإككترونية السياحية الرسمية"، واعتمدت الدراسة على اسلوب دراسة الحالة، مستخدمة منهج المسح حيث تم عمل تحليل كيفي للمواقع الاكترونية السياحية للأجهزة الرسمية، ومن أهم نتائج هذه الدراسة: - بعد الجهد المبذول من قبل المستخدم حقق أعلى الارجات، فبلغت نسبته في الموقع السياحي للبي (9\%، وفي الموقع السياحي لمصر 0,0؛ \% . - بعد تعدد الخيارات جاء في المرتبة الثانية بنسبة

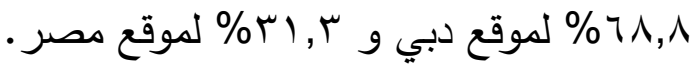

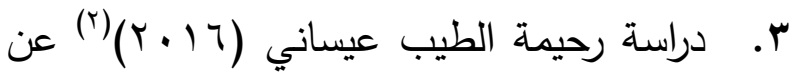
أشكال التفاعلية لدى مستخدمي شبكات التواصل الاجتماعي من الشباب العربي، هدفت الدراسة إلى

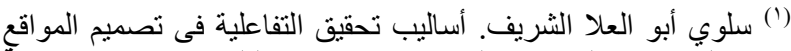

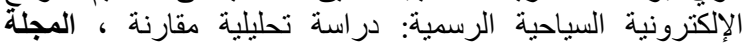

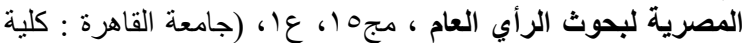

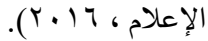

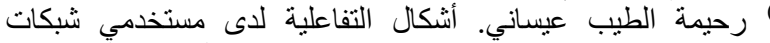

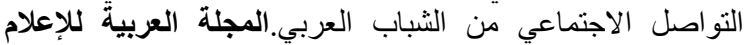

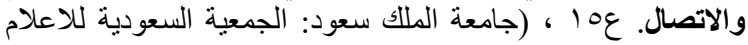

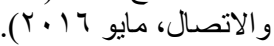


- - كان الإعجاب والتعليق وإدراج فيديو وصور من أهم معالم التفاعلية بالقناتين. - - يميل المشاركون إلى إخفاء هوياتهم، نظرا لما يتعرضون له من قمع لحرية التعبير .

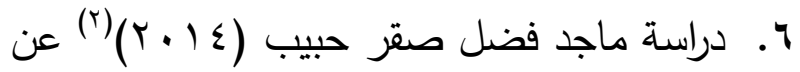
التفاعلية فى المواقع الالكترونية للصحف اليومية الفلسطينية، هدفت الدراسة إلى التعرف على مدى التكرئ

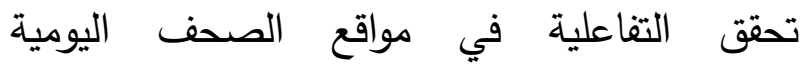
الفلسطينية على شبكة الانترنت، وتأتي هذه الدراسة في إطار الدراسات الوصفية مستخدمة منهج المسح

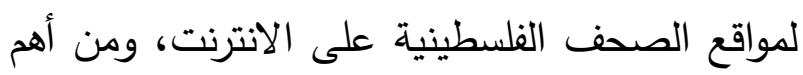
النتائج التى توصلت اليها الدراسة:- عدم انتهاج مواقع صحف الدراسة سياسة واضحة نحو التفاعلية. - حرصت مواقع الصحف على الترابط مع مواقع التواصل الاجتماعي. - - تستخدم مواقع الدراسة التفاعلية بطريقة غير مدروسة. - لم تسجل الدراسة اي فرصة لاى المستخدمين

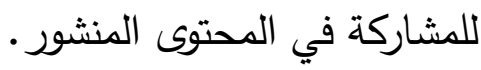

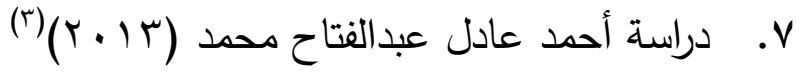
عن التفاعلية بالمواقع الالكترونية الصحفية

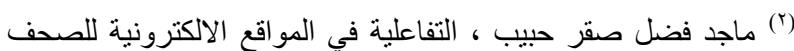

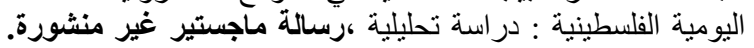
(خزة:الجامعة الاسلامية: كلية الآداب، ع الـالية كم).

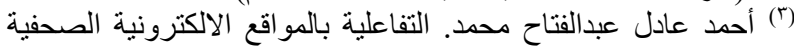

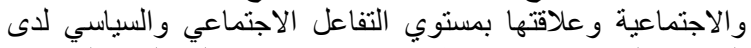

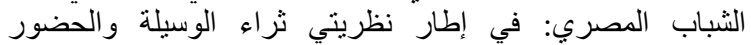

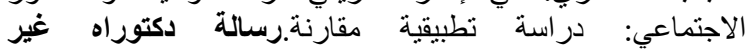

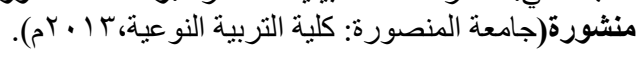

مواقع الثبكات الاجتماعية في المنطقة العربية، قامت هذه الدراسة التجريبية باختبار نظرية الاعتماد

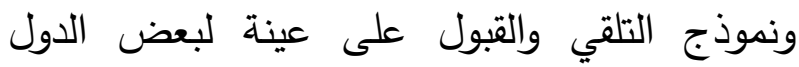

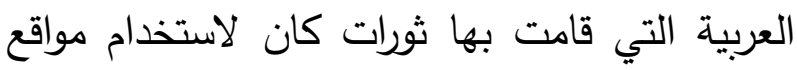
التواصل الاجتماعي اثرا كبيرا فيها وتحددت مشكلة لاندات هذه الدراسة فى معرفة العوامل المحيطة بعملية الإئية

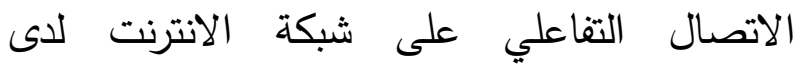

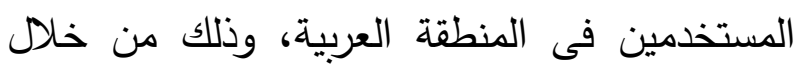
عدة اهداف الخاصة بالدراسة مثل: - تحديد الآليات التي تحكم التأثيرات الخاصة بمواقع الثبكات الاجتماعية على مستخدميها ودورها في تثكيل أولويات الفرد المستخدم لهذه الشبكات.

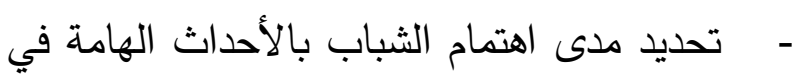
مجتمعاتهم وكيفية تفاعلهم معها من خلال مواقع التعائ التواصل الاجتماعي، ومن ابرز نتائج هذه الدراسة : - ثبوت صحة الفرض بعدم وجود فروق ذات الترات دلالة احصائية بين المبحوثين طبقا لمتغير المستوي

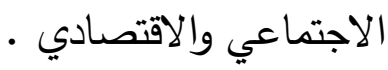

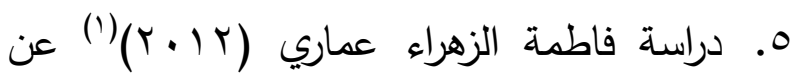
استخدام القنوات التلفزيونية الإخبارية التفاعلية لشبكات التواصل الاجتماعي، وهي دراسة وصفية استخدت منهج المسح التحليلي، لدراسة حالة قناتي FBC وF24، وتوصلت إلى عدة نتائج أههها:

' فاطمة الزهر اء عماري.استخدام القنوات التلفزيونية الاخبارية التفاعلية

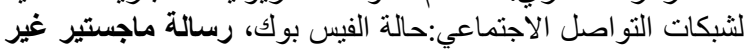

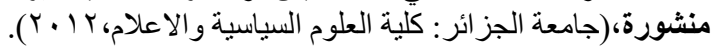


الإعلامية، في المواقع الإخبارية الفلسطينية، وهي دراسة وصفية استخدمت منهج المسح الثامل على الإعباه واحد وثلاثين موقعاً إخبارياً، ومن أهم النتائج:

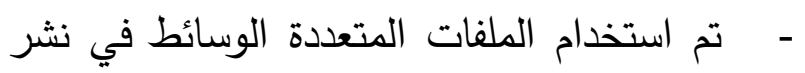
المواد الإخبارية. - غياب خاصية الدردشة مما يقلل من تفاعلية المواقع، وارتفاع نسبة خاصية إبداء الرأي. - كان هناك تحديث دائم للمواقع فيما تتشره.

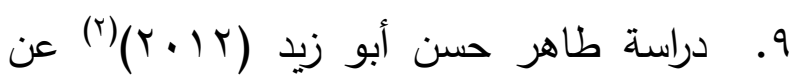
دور المواقع الاجتماعية التفاعلية في توجيه الرأي

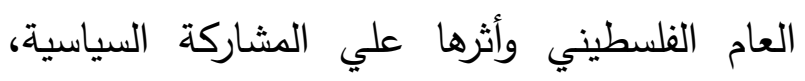
تتحور أهمية هذه الدراسة في أنها تدرس دور المواقع الاجتماعية التفاعلية في توجيه الرأي العام

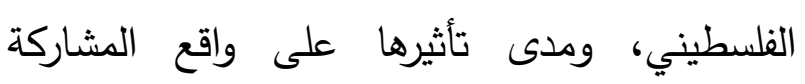
السياسية، لاسيما بعد النتائج الكبيرة التي حققتها

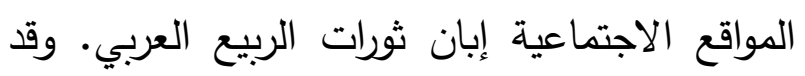

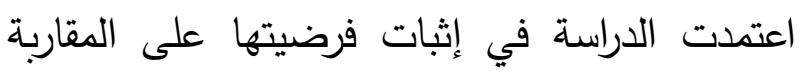

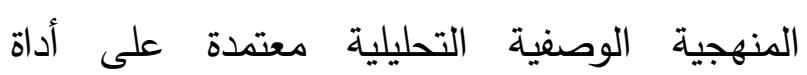

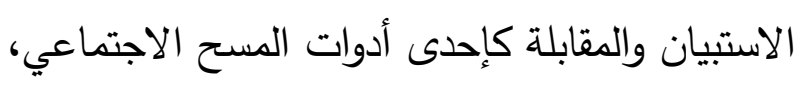
إلى جانب المنهج التاريخي ومنهج تحليل المضمون. وانتهات الدراسة بالاستنتاجات التالية:-
والاجتماعية وعلاقتها بمستوى التفاعل الاجتماعي والسياسي لدى الثباب، هدفت الى توصيف ما تقدمه

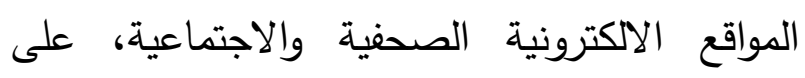
شبكة الانترنت من خدمات واليات تدعم التفاعل والمشاركة والاتصال بين كافة عناصر التئرن العملية الاتصالية المختلفة بالمواقع عينة الدراسة ومعرفة مدى ارتباطها بمستوى التفاعل الاجتماعي والسياسي لاى الثباب المصري، ومن نتائج هذه الدراسة:

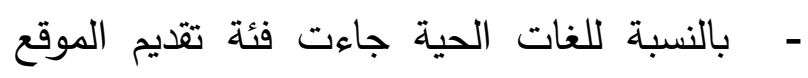

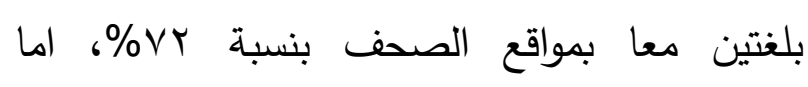
الشبكات الاجتماعية كانت بنسبة 0,ـ ؟7\%.

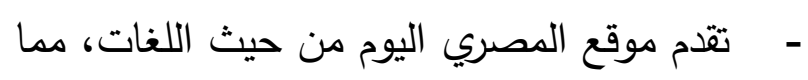
وسع قاعدة مستخدميها.

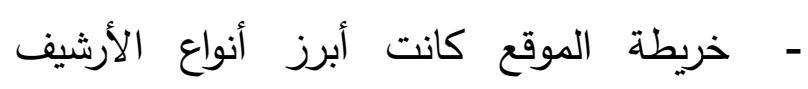
المستخدمة في المواقع عينة الدراسة.

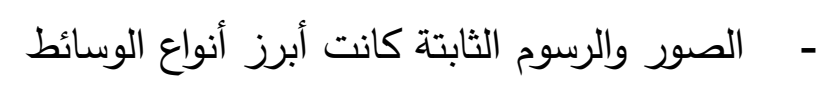
المتعددة. - الدردشة كانت أبرز آليات التفاعل بين المستخدمين.

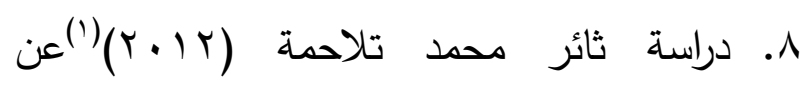

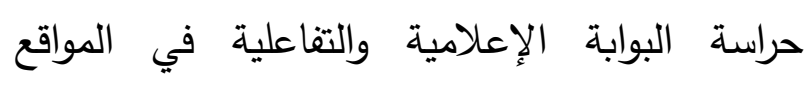
الإخبارية الفلسطينية على شبكة الإنترنت في المواقع الإعليه

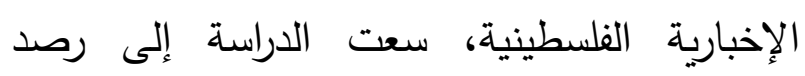
الإمكانات التفاعلية التي يتحها حارس البوابة لفئه

(1) ثائر محمد تلاحمة. حراسة البوابة الإعلامية والتفاعلية في المواقع

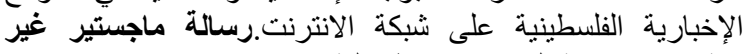

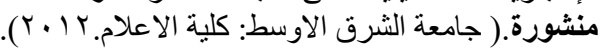

(T) طاهر حسن أبوزيد.دور المواقع الاجتماعية التفاعلية في توجيه الرأي التئي

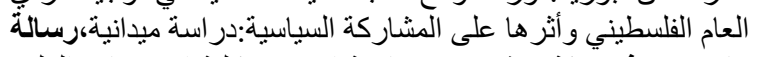

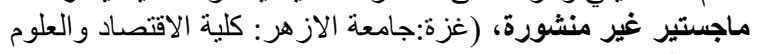

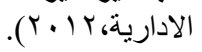


على شبكة الإنترنت، استهدفت هذه الدراسة التعرف على أنماط المجتمعات الافتراضية في الانترنت والسمات التي تميز كل نمط وحدود ما يمكن ان تقدمه من علاقة تفاعلية اجتماعية وثقافية بين سكان هذه المجتمعات الافتراضية على الإنترنت، وقد تم استخدام الملاحظة العلمية وتحليل المحتوى الكيفي لبعض المجتمعات الافتراضية، ومن أهم نتائج هذه الدراسة: - شبكات التعارف الاجتماعية مثل الفيسبوك أعادت صياغة العلاقة بين الانظمة المختلفة في المجتمع، كما أنها اضافات أبعاد جديدة للتواصل الاجتماعي بين الافراد داخل النظام، وكذلك استخدمت لحشد الجماهير المتفرقة جغرافيا وعقائديا للضغط على الانظمة السياسية للمطالبة بمزيد من الحقوق والتعبير بحرية عن الآراء والمعتقدات.

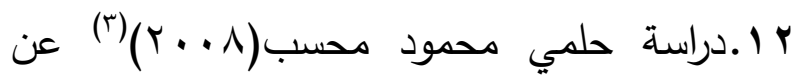
قياس تفاعلية المواقع التلفزيونية الإخبارية على الإنترنت، سعت الدراسة نحو قياس تفاعلية المواقع الاخبارية التلفزيونية على الإنترنت، باستخدام منهج المسح الإعلامي على موقعي الجزيرة و CNN، ومن نتائجه:

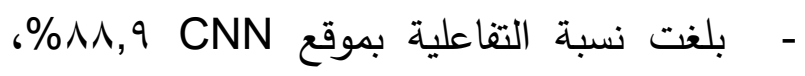
فيما بلغت بموقع الجزيرة, سه\%.

(") حلمي محمود محمد أحمد محسب. قياس تفاعلية المواقع التلفزيونية

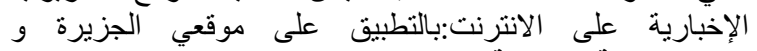

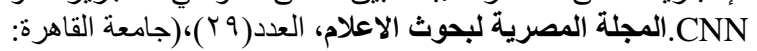

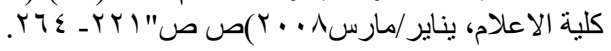

- تساهم المواقع الاجتماعية التفاعلية بشكل واضح في التأثير على توجهات الرأي العام في المجتمع الفلسطيني. - تؤثر المواقع الاجتماعية التفاعلية في زيادة

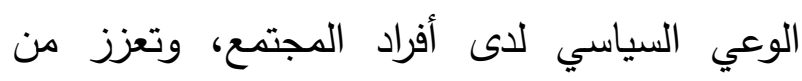
المسئولية الاجتماعية لديهم، مما انعكس إيجابيا على لولى لوني مستوى المشاركة السياسية. - المواقع الاجتماعية التفاعلية سيكون لها دور أكثر تأثيرا فى الحياه السياسية، وبشكل خاص فى الانتخابات الفلسطينية القادمة. • 1 . دراسة سعيد محمد الغريب النجار (9 . . ץ)(1) عن التفاعلية في الصحف العربية على الإنترنت، استهدفت الدراسة التوصل إلى مدى تحقق التفاعلية في الصحف العربية الإلكترونية، وهي دراسة وصفية كمية، ومن أهم نتائجها: - - الصحف العربية الإلكترونية الخالصة تحقق مستويات تفاعلية أكبر من الصحف ذات الأصول

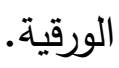
- حققت نسبة ب^^\%، من الصحف عينة الدراسة مستوى تفاعلية تراوح ما بين (7-1 (ادرجة).

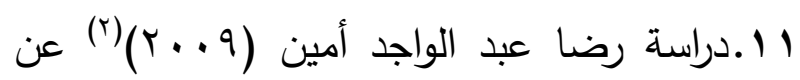
حدود التفاعل الاجتماعي في المجتمعات الافتراضية

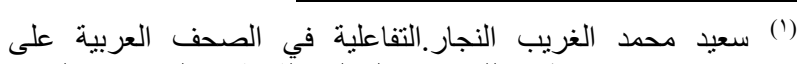

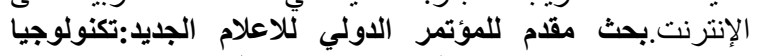

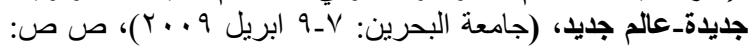
.01T_009

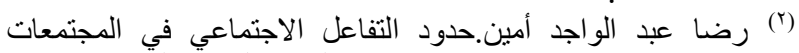

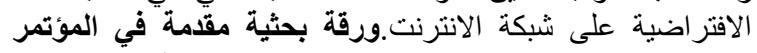

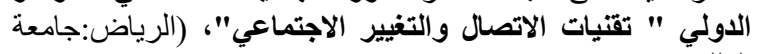

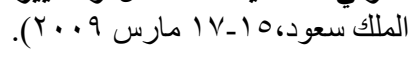


ب. المحور الثاني: دراسات تناولت المواقع الإكترونية الحديثة وعلاقتها بتشكيل اتجاهات الجماهير ومشاركتهم وتفاعلهم نحو القضايا الهامة.

1- دراسة حاتم علي حيدر مقبل الصالحي

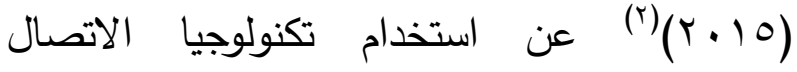
التفاعلي، هدفت الدراسة إلى رصد وتقييم واستخدام المنظمات العاملة في اليمن لتكنولوجيا الاتصال التفاعلي وتحديدا المواقع الالكترونية والفيس بوك، من خلال تحليل محتوايات صفحاتها، وتم اختيار العينة بطريقة عمدية لتقييم قدراتها التفاعلية

$$
\text { والحوارية، وتم التوصل إلى: }
$$

- تعزز التفاعلية المشاركة وبناء العلاقات بين

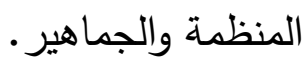

- التفاعلية تخلق جاذبية للمواقع الالكترونية. - التفاعلية تجعل المستخدمين يشعرون بالقرب

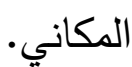
- - مالتفاعلية تؤثر على الرضا والاستجابة المدركة والاتجاهات بشكل عام نحو المواقع. r - دراسة هشام سعيد فتحي عمر البرجي

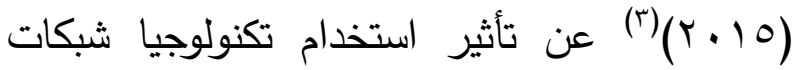
التواصل الاجتماعي، استهدف فيها الباحث التعرف

(r) حاتم علي حيدر مقبل الصالحي.استخدام تكنولوجيا الاتصال التفاعلي

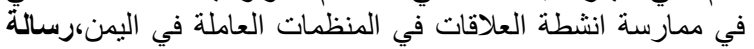

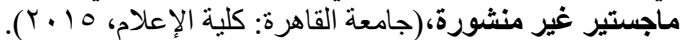

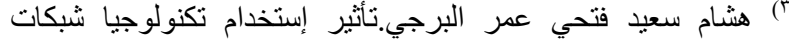
التواصل الاجتماعي عبر الانترنت على العلاقات الإنير الاجماعية للأسرة

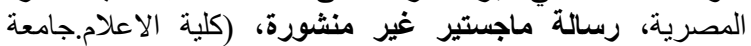

- تقوق موقعCNN على موقع الجزيرة في بعد تعدد الخيارات المتاحة بنسبة V9,v\% rا. دراسة (r)Jens Jensen التفاعلية: تتبع مفهوم جديد فى الدراسات الإعلامية والاتصالات حاولت هذه الدراسة تقديم مفهوم واضح ومتقق عليه للتقاعلية، ملقيا نظرة على التعريفات الموجودة سابقا عن التفاعل وحدد ثلاث طرق لتعريفه إما عن طريق اعتبار التفاعل مثال نموذجي، أو كمعيار وخاصية مميزة، أواعتباره سلسلة متصلة بمعنى جودة يمكن أن تكون متواجدة بدرجة أكبر أو أقل، وحاول الباحث عمل حصر لكل الابعاد المقترحة للتفاعلية من الباحثين الآخرين. وقد أشارت هذه الدراسات فى مجملها إلى أنها تدرس دور المواقع الاجتماعية التفاعلية في توجيه الرأي العام، وحاولت كل الدراسات رصد الأدوات والأشكال التفاعلية بالمواقع عينة كل دراسة، كما حاولت بعض الدراسات رصد استخدام الأفراد للأدوات التفاعلية بالمواقع، وسعت بعض الدراسات إلى رصد الإشباعات المتحققة لدى الجماهير وحاولت بعض الدراسات التوصل إلى العلاقات التي تربط ما بين التفاعلية، وزيادة المشاركات الاجتماعية والسياسية، ولم تحاول دراسات كثيرة إجراء دراسات مقارنة في مجال استخدام الأدوات التفاعلية، فى المواقع الأجنبية.

\footnotetext{
(1)Jensen, J.F. " Interactivity-tracking a new concept.Op.Cit.
} 


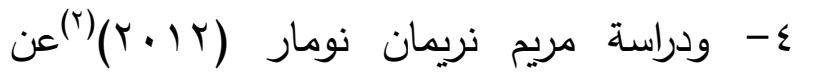
استخدام مواقع الثبكات الاجتماعية وتأثيره في تربي العلاقات الاجتماعية دراسة عينة من مستخدمي موقع الفيس بوك في الجزائر، هدفت الدراسة إلى الى الكي الكثف عن أثر استخدام مواقع الثبكات الاجتماعية التانية فى العلاقات الاجتماعية، وتم تطبيق أداة الاستبيان

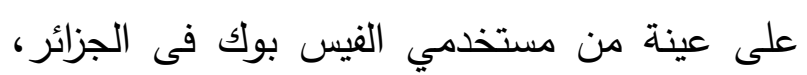
وتوصلت الدراسة إلى عدة نتائج أهمها:

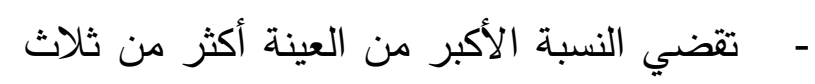
ساعات في استخدام الفيس بوك. - حازت خدمة التعليق والدردشة على المراكز الاولى لاى تفضيلات المبحوثين. - التواصل مع الاهل والتثقيف كان غاية المستخدمين للفيس بوك.

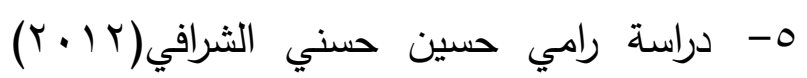

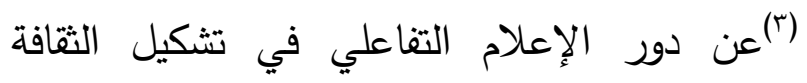
السياسية لدى الثباب الفلسطيني، هدفت الدراسة بشكل رئيس إلى التعرف على الدور الذي يقوم به

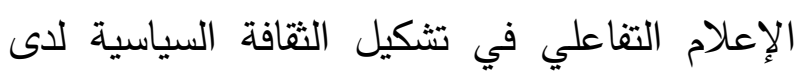
الشباب الفلسطيني في قطاع غزة. وطبقت الدراسة على عينة من الطلبة في الجامعات الفلسطينية،

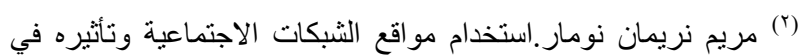

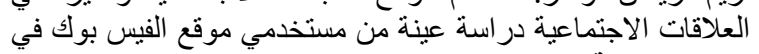

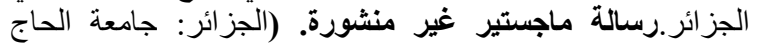

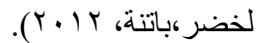

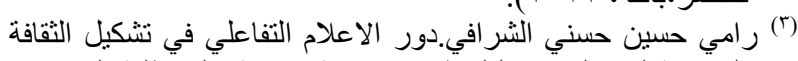

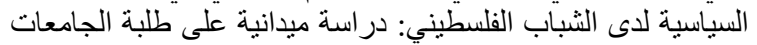

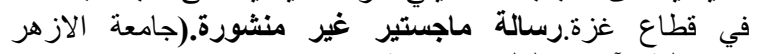

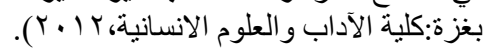

على مدى تأثير شبكات التواصل الاجتماعي عبر الانترنت على العلاقات الاسرية، وتم استخدام منهج الإنج

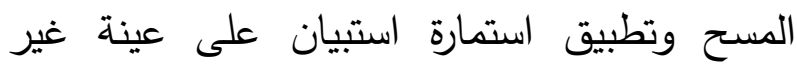
احتمالية من افراد الاسرة المصرية، وانتهى البحث

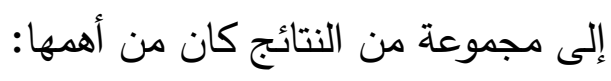

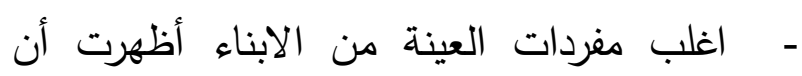
موقع الفيس بوك جاء في المركز الاول بعدد نقاط الاناء

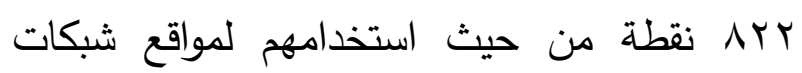

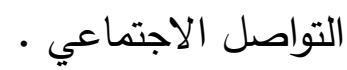
- - أكدت النتائج عدم استخدام المبحوثين من الآباء

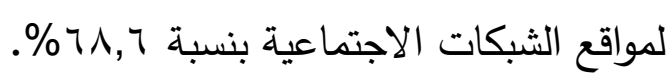

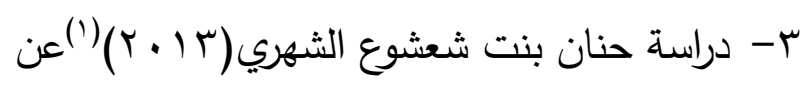

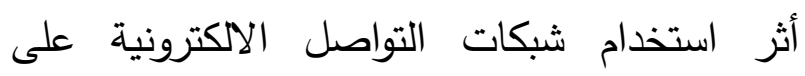
العلاقات الاجتماعية: الفيس بوك وتويتر نموذجا، التاني هدفت الدراسة إلى التعرف على الاسباب التي تدفع التعات

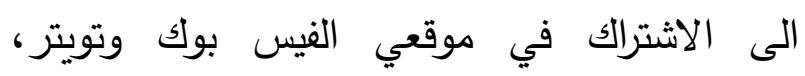

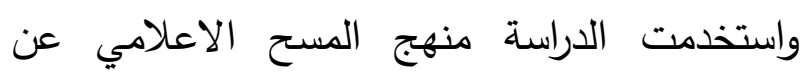
طريق الاستبيان، وكانت من اهم النتائج الآتي:

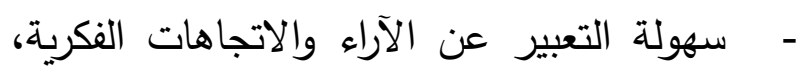
هي اقوي الاسباب لاستخدام الثبكات الاجتماعية.

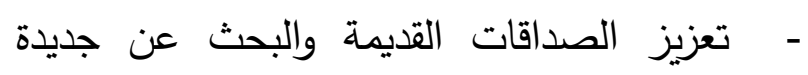
كانت من اهم الاسباب ايضا. - الانفتاح الفكري والتبادل الثقافي اعتبرنه الدبحوثات من الاسباب الايجابية.

(') حنان ينت شعشوع الثهري. أثر إستخدام شبكات الثو اصل الالكثرونية

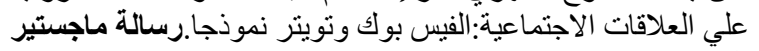

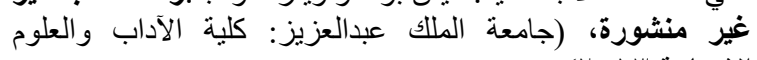

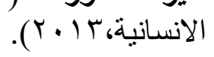


- معلومات حول الأحداث التي أدت إلى إنى الاحتجاجات انتشرت إلى حد كبير من خلال تقنيات وسائل الاعلام الاجتماعية.

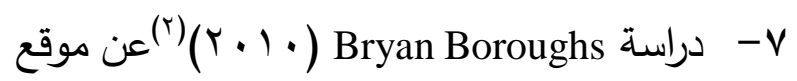
الشبكات الاجتماعية والإقبال على التصويت، هدفت الدراسة إلى استبيان الدور التي تقوم به مواقع الشبكات الاجتماعية في دفع المستخدمين إلى الإقبال على التصويت في الانتخابات الرئاسية في الولايات المتحدة الأمريكية، وقد أجريت الدراسة على عينة من الجمهور العام قوامها \& Y r مفردة، واعتمدت الدراسة على التحليل الكمي، واستقصت الدراسة فترة ما بعد انتخابات ^ . . r. وقد توصلت الدراسة إلى عدة نتائج من أهمها: - توجد علاقة ارتباطيه دالة إحصائياً بين التعرض مل للمحتويات السياسية فى مواقع الشبكات الاجتماعية واحتمالية التصويت في الانتخابات. - - تساهم مواقع الشبكات الاجتماعية إسهاماً كبيراً في دفع الجمهور الذي ليست لديه أية اهتمامات سياسية إلى التصويت في الانتخابات

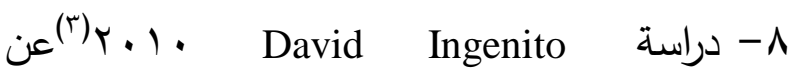
الديمقراطية في القرن الحادي والعشرين: الإعلام الاجتماعي والسياسة، هدفت الدراسة إلى الكثف عن

(2) Boroughs,B.S."Social Networking Websites and Voter Turnout ".Unpublished M.A (Washington ,D.C : Georgetown University.2010).

(3 Ingenito,D."Democaracyin21st Century :Social Media and Politics-global village or cyberbalkans?" Unpublished M.A.( Los Angeles ,CA:University of Southern California .2010).
واستخدم الباحث منهج المسح لعينة مكونة من ب9؛ طالبا وطالبة، وكانت أهم النتائج ما يلي:- أظهرت الدراسة أن الفيس بوك أكثر وسائل الإعلام التقاعلي استخداماً لدى المبحوثين من طلبة الجامعات الفلسطينية في قطاع غزة، يليه في المرتبة الثانية البريد الإكتروني، ثم اليوتيوب، وبنسب متفاوتة تويتر والمدونات. - كثفت الدراسة ان نسبة • من العينة يثقون في الاعلام التفاعلي للوصول إلى المعلومات. - أوضحت الدراسة أن الاعلام التفاعلي لله دورا ايجابيا في تشكيل الثقافة السياسية بنسبة تصل إلى

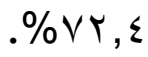

Nahed El Tantawy \& Julie B.Wiest

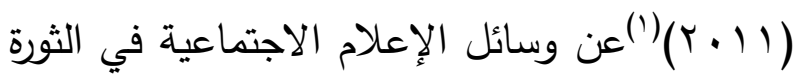
المصرية،، حاولت هذه الدراسة من خلال دراسة حالة محدودة، استكثاف وسائل الاعلام الاجتماعية، وقد برهنت الدراسة أن وسائل الاعلام الاجتماعية لعبت دورا اساسيا في نجاح الاحتجاجات ضد الحكومة، ومن أهم نتائج هذه الدراسة: - قدمت وسائل التواصل الاجتماعي موردا جديدا قدم السرعة فى تلقي المعلومات ونشرها؛ لبناء وتعزيز الروابط بين الناشطين.

\footnotetext{
${ }^{(1)}$ Nahed El Tantawy \& Julie B.Wiest.Social Media in The Egyptian Revolution:Reconsidering Resource Mobilization Theory. International Journal of Communication 5 (2011). pp 1207-1224.
} 
عليها، وبالإضافة الى عمل مقارنة بين الاشباعات التي تم الحصول عليها من قبل المستخدم، وما هو مطلوب منه اثناء التداول على تويتر. ومن اهم النتائج التي حصل عليها الباحث:

- تم تحديد عاملين هامين لاستخدام تويتر متمثلين في الدوافع الاجتماعية الدوافع المعلوماتية.

- وجد الباحث في تحليله أن دافع المعلوماتية هو هم المستخدم الأكبر من استخدام تويتر . - الدوافع الاجتماعية لم تكن هي أهم ما يسعي اليه مستخدم تويتر •

- - تشير البيانات الي أن تويتر يستخدم في المقام الاول كمدر للمعلومات، وليس كوسيلة لتلبية الاحتياجات الاجتماعية.

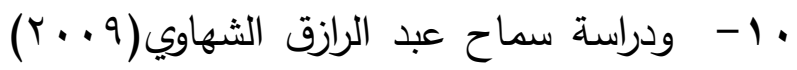
(r) عن علاقة التفاعلية باستخدام الثباب للمواقع الموجهة لهم علي شبكة الانترنت دراسة ميدانية علي الجمهور والقائم بالاتصال، اعتمدت الباحثة على عينة من الثباب الجامعي المصري من مستخدمي الانترنت، وقد اعتمدت الباحثة علي العينة الطبقية فهي تستخدم لدراسة فئة أو شريحة معينة من المجتمع، وقد أجريت الدراسة علي عينة حجمها • 0 ـ مفردة بواقع . 10 مفردة لكل جامعة، وهدفت الدراسة الي التعرف علي استخدامات الشباب

r سماح عبدالرازق الثهاوي.علاقة التفاعلية باستخدام الثباب للمواقع

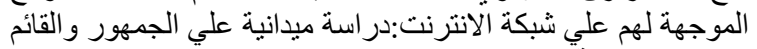

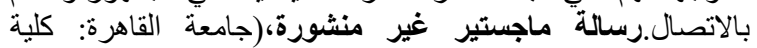

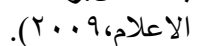

تأثير ما يتم نشره من موضوعات وروابط إلكترونية ومقاطع الفيديو وصور في مجموعات النقاش في موقع الفيس بوك في الدور السياسي لهذا الموقع ، وقد تم تحليل مضمون مائتي مجموعة من مجموعات النقاش. وقد توصلت الدراسة إلى عدة

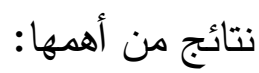
- أن مجموعات النقاش في موقع الفيس بوك هي منتديات لحوار الفعال بين المستخدمين في

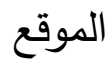
- يسهل الموقع عمليه الحوار الديموقراطى؛ لكونه يفرد مساحات افتراضية لمناقشة موضوعات سياسية مختلفة. - - تحليل المضمون أوضح أن الفيس بوك قادر علي اجتذاب الأجيال القادمة للخطاب السياسي فيه لكونه مالائما لهم له

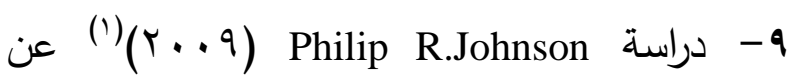
الاستخدامات والإشباعات من تويتر: دراسة عن دوافع المستخدم ومدى رضاه عن استخدام تويتر، طبق الباحث نظرية الاستخدامات والإشباعات علي موقع تويتر للخروج بنتائج عن مميزات موقع تبادل المعلومات عن طريق التدوينات القصيرة والسريعة، وسعي الباحث لدراسة دوافع المستخدم ومدي الرضا عن الموقع، ومدى الاشباعات التي تم الحصول

(1) Philip R.Johnson.Uses and Gratifications of Twitter: An Examination of User Motives and Satisfaction of Twitter Use.september.2009. available at: https://www.researchgate.net/publication/228959 $\underline{109}$ 
- أن الدوافع الرئيسة للدخول على الصفحات الشخصية للمرشحين في موقع ماى سبيس هو

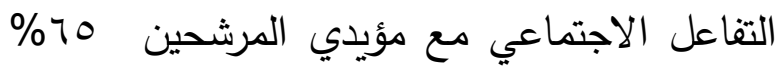
وفى بعض الأحيان المرشحين أنفسهم.

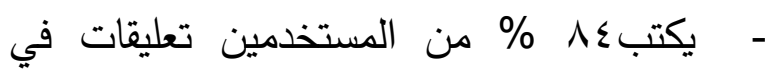

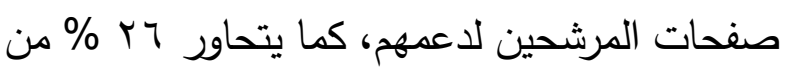
المستخدمين مع مؤيدي المرشحين.

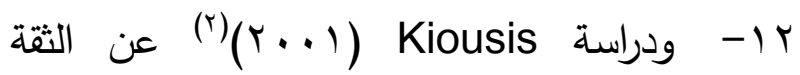
العامة أو انعدام الثقة، ناقش "Kiousis" في دراسته معيار الثقة كأحد المحددات التي يستخدمها الجمهور عند متابعته لوسائل الإعلام الجديدة فى عصر المعلومات، وقد قارن الباحث في دراسته بين مصداقية الأخبار المستقاة من التليفزيون والصحف وشبكة الإنترنت. وقد عرض لمتغيرين مهمين هما

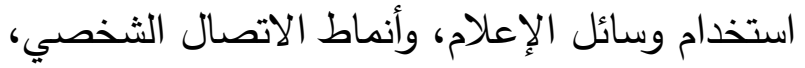
ودورهما فى مناقشة مصداقية الوسيلة، وقد ركز أيضاً على مصداقية المصدر والمحتوى، وقد استخدم الباحث منهج المسح الإعلامي لعينة عشوائية، و

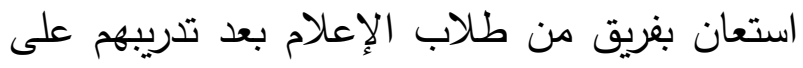
إجراءات البحث، ومن أهم نتائج هذه الدراسة:

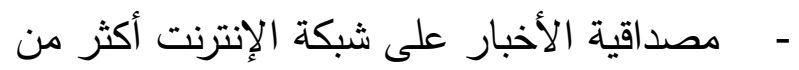

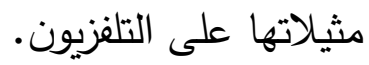

(2 )Kiousis, S.(2001-Nov.)" Public Trust or Mistrust? Perceptions of Media Credibility in the Information age." Journal of Mass Communication \& Society.p.p 4(4).
للأدوات التفاعلية التي تتيحها شبكة الانترنت بشكل

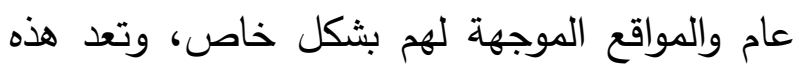
الدراسة من الدراسات الوصفية حيث تهتم برصد لهدئ وتوصيف الأدوات التفاعلية فى المواقع الموجهة لاتهية للشباب على الانترنت، واستخدمت منهج المسح والمنهج المقارن. وكانت من أهم النتائج التى خلصت الترن

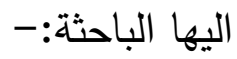

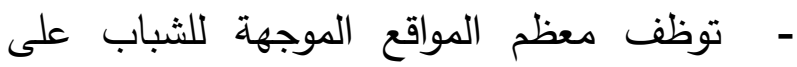
شبكة الانترنت • 9\% مستوي للتفاعلية. - لم توظف كل المواقع محل الدراسة أشكال الاتصال التزامني كخدمة الدردشة بينما وظفت هذه المواقع أشكال الاتصال اللاتزامني وفي مقدمتها جاء وجود المنتديات الالكترونية، ثم امكانية إرسال الصفحة أو الموقع لمستخدم آخر •

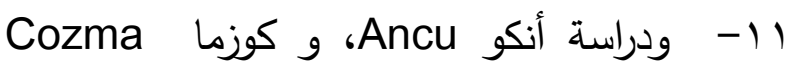

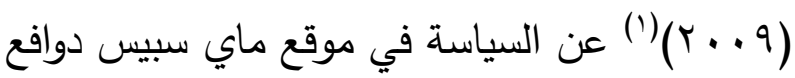
الاستخدامات والإثباعات المتحققة من مصادقة المرشحين السياسيين فى المواقع،هدفت الدراسة إلى مالى قياس دوافع الاستخدامات، والإثباعات المتحققة من لفن دخول المستخدمين على الصفحات الثخصية للمرشحين السياسيين في الموقع، وقد طبقت الدراسة على عينة عمدية من المستخدمين من زائري الصفحات الشخصية للمرشحين، ومن أهم نتائج هذه

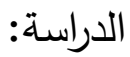

(1 )Ancu ,M \& Cozma ,R R ." Myspace Politics :Uses and Gratifications of Befriending Candidates

.In : "journal of Broadcasting \& Electronic Media" . Vol.53,No.4,December 2009.pp.567-583 . 
على تأثير المواقع الإلكترونية الحديثة على الجمهور

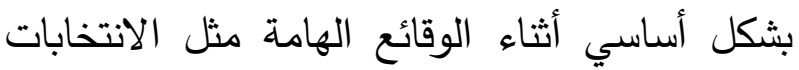
الرئاسية والتصويت عليها،وسعت الدراسات العربية إلى التعرف على الدوافع إلى استخدام المواقع الإكترونية الحديثة، والتعرف على مواقف الثباب

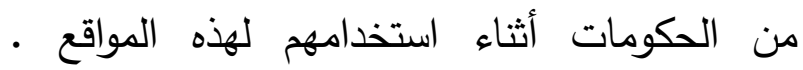
وتعاملت معظم الدراسات مع فئة الثباب كعينة للدراسة، وطبقت معظم الدراسات على شبكات التواصل الاجتماعي وخاصة الفيس بولك، مختزلة بذلك الأدوات التفاعلية على الثبكات الاجتماعية،

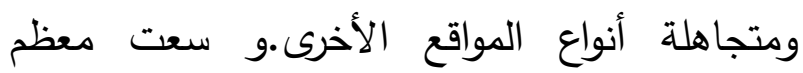
الدراسات لربط الأحداث السياسية الجارية بالثبكات التهات الاجتماعية، كسبب للحشد والتعبئة، وليس كوسيلة، ولم تسع الدراسات الحديثة إلى دراسة مواقع جديدة ومتتوعة، واستخدام الجماهير لها، ولكنها وصفت طبيعة العلاقة بين الاعتماد على المواقع الإخبارية الإلكترونية ومستوى المعرفة بالقضايا السياسية تعقيب عام على الدراسات السابقة ومدى الاستفادة منها فى الدراسة الحالية استفادت هذه الدراسة من الدراسات السابقة فى عدة نقاط: (أ) الجانب النظرى: من خلال التعرف على النظريات المستخدمة لدراسات الإنترنت وما يحتويه من مواقع إخبارية وشبكات إجتماعية و...إلخ، والعينات الأكثر شيوعا وطرق سحبها، والإشكاليات

$$
\text { التى طرحت حولها. }
$$

تشكيل اتجاهات الجمهور بشأن مصداقية وسائل الإعلام التقليدية.

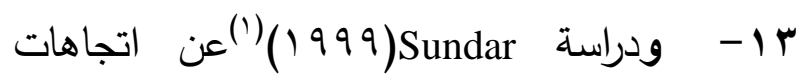
الجمهور نحو استقاء الأخبار من مواقع الإنترنت ومن وسائل الإعلام التقليدية ومن خلال دراسته التجريبية على مجموعتين من طلاب الصحافة والإعلام قام الباحث باختبار أربعة متغيرات وهى ملئ

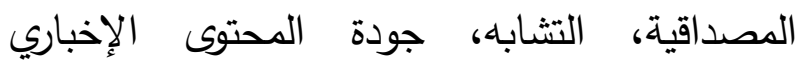
،ودرجة تمثيل الأخبار للحقيقة، وقد توصل الباحث إلى أن: الأخبار المطبوعة والأخبار الفورية من مواقع الإنترنت تخضع لنفس معايير المفاضلة لدى القراء، وقد اشتملت هذه المعايير على: الموضوعية، عدم لإنراير التحيز، التشويق، الإثارة، المتعة، السهولة، الوضوح،

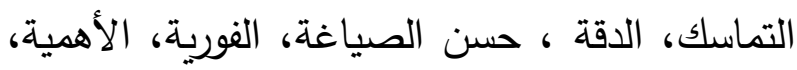
المصداقية، العمق المعلوماتي والثمولية. واهتم الجانب المستقبلي فى هذه الدراسة بالدعوة لابتكار مقاييس جديدة تعالج قضية مصداقية وسائل الإعلام

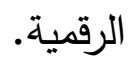
وقد سعت هذه الدراسات فى مجملها إلى التعرف

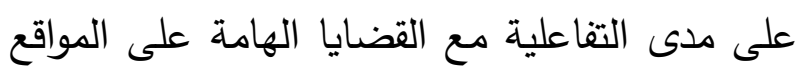
الإلكترونية الحديثة، والبحث عن حريات التعبير والاستخدام لهذه المواقع، وركزت الدراسات الأجنبية

(1 ) Sundar, S. (1999. Summer) "Exploring Receivers' Criteria for Perception of Print and Online news." Journalism \& Mass Communication Quarterly. 76 (2). Pp: 373-386. 
حقائق عنها، هى "التفاعلية فى الصفحات الإخبارية بالثبكات الاجتماعية"، وعلاقتها بمستوى المشاركة الجماهيرية"، حيث قامت الباحثة بتحديد موضوع بهابـ الدراسة عن طريق بعض الدراسات التحليلية والميدانية لمعرفة خصائص الظاهرة وتحديدها كيفاً

منهج الاراسة

Survey استخدمت الباحثة منهج المسح Method والتحليلي "Analytical"، لتحقيق التكامل المنهجي، ولوصف طبيعة وسمات وخصائص العينة والظاهرة المحيطة بها. وهى تحليل التقاعلية كمنتج وعملية للوقوف على طبيعة ومستوى استخدام الأدوات التفاعلية فى الصفحات الإخبارية بالثبكات الاجتماعية ودورها في استقطاب الجمهور وتكوين

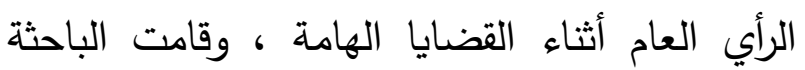
بالوقوف على أغلب الأدوات التفاعلية، لمعرفة أيها الأكثر استخداما. وتم استخدام منهج المسح الإعلامي من خلال: المال - مسح الظاهرة: وقد استهدف تسجيل وتفسير وتحليل الظاهرة، وبذلك شملت الدراسة أكبر عدد من الحالات موضع الدراسة، حيث أن منهج المسح يعتبر جها منظما، للحصول على بيانات وأوصاف

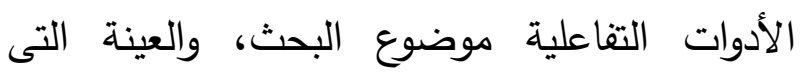
شملتها الدراسة، وبذلك استخدمت الباحثة "تحليل المضمون"، وذلك بعمل تحليل كيفي وكمي لأدوات
وأفادت أيضا فى معرفة الأطر النظرية حول ظاهرة التفاعلية وتفسيرها بمواقع الإعلام الجماهيري، وكيفية صياغة المقاييس لقياسها، وحصر أدواتها. وتحديد عينة لم يتم تتاولها من قبل بالنسبة لاستخدام الأدوات التفاعلية بالشبكات الاجتماعية. (ب) الجانب المنهجى: أفادت الدراسات السابقة الباحثة فى تحديد البناء المنهجى لهذه الدراسة من حيث تقسيم محاور الدراسة وتحديد منهجها وعينتها وصياغة تساؤلاتها والتحليلية وتحديد الأدوات ولتهات المستخدمة لجمع البيانات وللوصول لنتائج تخدم

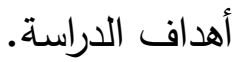
موقع الدراسة الحالية من الدراسات السابقة: (أ) اتفقت هذه الدراسة مع الدراسات السابقة فى: استخدام التفاعلية كمتغير مستقل يراد دراسة تأثيره على متغيرات تابعة، استخدام الأبعاد الستة للتفاعلية كما وضعتها " كاري هييتر" مع بعض التعديلات

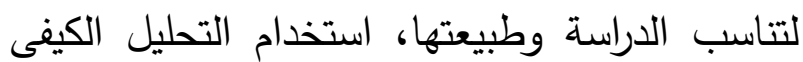
والكمى كان الأنسب لأن مواقع الدراسة تتسم بالثبات

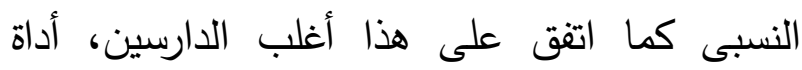
تحليل المضمون كانت الأنسب لهذه الدراسة كما لها لهاني الدراسات السابقة أيضاً. (ب) اختلفت هذه الاراسة مع الدراسات السابقة فى: محاولة فهم التفاعلية كمنتج وعملية فى آن واحد.

نوع الدراسة

Descriptive تعد هذه الدراسة دراسة وصفية study حيث تستهدف وصف ظاهرة معينة وجمع 
التفاعلية على الصفحات عينة الدراسة، بشكل كيفي وكمى، ويضمن الإلمام بأغلب أشكال التفاعلية المتاحة على تلك الصفحات. • معايير اختيار العينة التحليلية: قامت الباحثة بتحليل صفحات BBC News) بالعربية و France 24 بالعربية) ، وفقا لعدة معايير انطبقت عليها، وجعلت منها مواقع يمكن الخروج منها بنتائج تحقق أكبر فائدة درجوة لهذه الدراسة وذلك: - بعمل دراسة استطلاعية بينت أن هذه المواقع هي الأكثر استخداما لدى عينة الدراسة. ثانيا: عينة الاراسة الزمنية: امتدت فترة الدراسة التحليلية لمدة شهر لكل الصفحات الإخبارية بالثبكات الاجتماعية، بدأت من

$$
\text { الفترة } 0
$$
وقد اختارت الباحثة فترة شهر كامل لكل نوع من هذه المواقع لعدة مبررات وهي كالآتي: - كانت الفترة التى اختيرت مواكبة لمجريات الدراسة، كما أن الفترة الزمنية الحديثة تتيح الوقوف على أهم التطورات التكنولوجية التى طرأت على هذه المواقع، قيد الدراسة وعناصر التفاعلية المختلفة التى

$$
\text { يضمها كل موقع. }
$$

- امتدت الفترة لمدة شهر كامل، لمحاولة لحصر كل الأدوات التفاعلية بكل موقع، وكانت موحدة لكل الصفحات الإخبارية، على موقعى الدراسة، فى لى لـ
التفاعلية وعناصرها وآلياتها وأبعادها بالصفحات الإخبارية بالشبكات الاجتماعية. مجتمع الدراسة

- مجتمع الدراسة التحليلية : تمثل في صفحتي ال بالعربية و 24 BBC News على موقعى فيس بوك وتويتر . عينة الدراسة انقسمت عينة الدراسة إلى ثلاثة انواع: أولا: عنة الاراسة التحليلية : تمثلت فى رصد جميع أدوات وآليات التفاعلية بالصفحات الإخبارية على الفيس بوك وتويتر

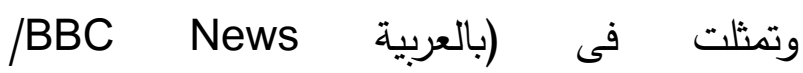
بالعربية France 24$)$ وذلك لمدة شهرة كامل امتد من الفترة 0 بتحليل هذه الصفحات لحصر أكبر قدر من الأدوات التفاعلية، وفى محاولة للوصول إلى أغلب أنواعها، أو ما يمثل كل أبعادها، نظرا لما يميز الإنترنت و مواقعه من تشعب يصعب حصره، وقد تمثلت مبررات اختيار هذه العينة فيما يلي: - عملية الحصر التى قامت بها الباحثة للدراسات السابقة فى نفس المجال ومجالات مشابهة وقربية، بينت أن هذه الصفحات الإخبارية بالشبكات الاجتماعية هى من أكثر الصفحات استخداما وشعبية. - اختارت الباحثة فترة شهر كامل، لتحقيق دورة زمنية كاملة تتيح مدى زمنياً مناسباً لدراسة الأدوات 
من خلالها تحليل المحتوى الظاهر للمادة الإعلامية بالصفحات الإخبارية بالشبكات الاجتماعية، فى فئ محاولة للإجابة على تساؤلات الدراسة التحليلية، طبقا لمقياس "كاري هيتر" ذى الأبعاد الستة للتفاعلية، وقد استندت الباحثة فى جمعها للبيانات على الأسلوب الكيفي والكمي، من أجل التعرف على آليات التفاعلية وأدواتها التى توظفها الصفحات الإخبارية، وقد تم تحكيم الاستمارة من قبل مجموعة من الأساتذة المحكمين فى مجال الإعلام للخروج بأدق صياغة وشكل للأسئلة.

- مقياس التفاعلية الوظيفية: اعتمدت الباحثة على مقياس "كاري هيتر"، ذي الأبعاد الستة لقياس التفاعلية الوظيفية بالصفحات الإخبارية، متمثلة فى أدواتها التفاعلية المتوفرة بها، وتعزز من إمكاناتها وقدراتها، وقد عدلت وأضافت بعض المصطلحات والمفاهيم على هذا المقياس؛ ليتناسب مع العناصر التكنولوجية الحديثة، التى طرأت على هذه المواقع، مما ساعد فى حصر أغلب الأدوات التفاعلية فى

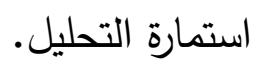
الإطار الإجرائي للاراسة التحليلية لتصميم وتطبيق استمارة تحليل المضمون، وللوصول إلى نتائج دقيقة لهذه الدراسة، قامت الباحثة بعدة خطوات إجرائية متمثلة في:- إجراءات تصميم استمارة تحليل المضمون: اتبعت الباحثة عدة خطوات لتصميمها وهى كالتالي:
محاولة للحصول على نتائج بها صدق وموضوعية للدراسة التحليلية. معايير اختيار العينة الزمنية:

اختارت الباحثة الفترة الزمنية الخاصة بالدراسة التحليلية وفقا لمعيار واحد وهو: - أن تكون هذه الفترة آنية؛ أي مواكبة لفترة إجراء الدراسة التحليلية بشكل خاص وللدراسة ككل بشكل عام. ثالثا: عينة الدراسة الموضوعية: تمثلت فى قضيايا "الأحداث الجارية بالسودان" و "الأحداث الجارية بالجزائر" و وحريق عنيسة

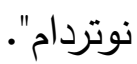
أدوات جمع البيانات بالدراسة: وتتمثل أدوات جمع البيانات لهذه الدراسة فى أداة أساسية (') هيى:

أ. استمارة تحليل المضمون: وهى أداة منهجية علمية تستخدم بشكل واسع فى الدراسات الإعلامية لتحليل المضامين الظاهرة- شكلا ومضمونا- لما ينشر أو يبث عبر وسائل الإعلام. ويعرف هذا الأسلوب بأنه "الوصف المقنن للمحتوى الظاهر" وقد أعدت الباحثة استمارة لتحليل المضمون، استطاعت

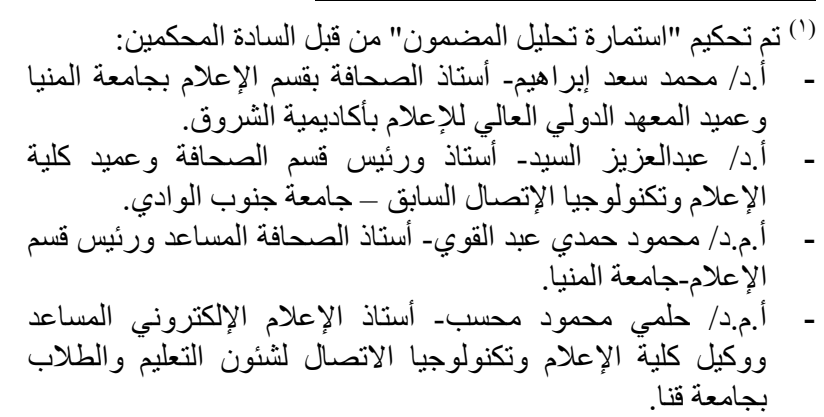


- تحكيم الاستمارة: عرضت الباحثة الاستمارة

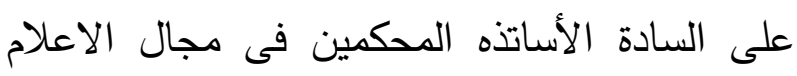
أولا لإبداء ملاحظاتهم عليها، وفى النهاية تم تعديل الاستمارة وفقا للآراء المعروضة للوصول للشكل النهائي الذى تم التحليل بناءً عليه.

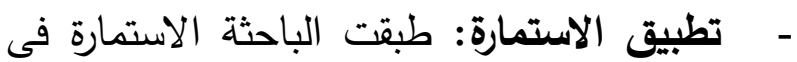
صورتها النهائية على عينة الدراسة؛ حيث تم ملء خانات الاستمارة بالنسبة لكل صفحة، ثم تفريخ البيانات وجمعها فى جداول وتحليلها وبذلك تم الخروج بتكرارات ونسب مئوية لكل فئة. اختبارا الصدق والثبات

" صدق الاستمارة: للتأكد من صدق استمارة التحليل الظاهري، وللتأكد من قدرتها على تحقيق أهداف الدراسة، واختبار فروضها، والخروج بنتائج ذات معنى فيما يخص مجال الدراسة؛ تم عرضها على مجموعة من المحكمين لها، وتم اختيارهم وفقا لتخصصهم فى مجال الدراسة؛ للتأكد من مناسبتها لقياس الفئات بدقة.

"ثبات التحليل: تم تطبيق استمارة تحليل المضمون على فترتين متساويتين متباعدتين قدرتا بخمسة عشرة يوما على نفس المواقع عينة الدراسة، وبالخروج بنتائج متشابهة، فى المرتين تم التأكد من

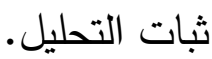

\section{المعالجة الإحصائية للدراسة}

بالنسبة للاراسة التحليلية: استخدمت الباحثة أسلوب التكرارات البسيطة، والنسب المئوية الخاصة بكل
- جمع المادة العلمية حول الاستمارة: قامت الباحثة بالاطلاع على الأدبيات السابقة فى مجال الدراسة والدراسات ذات الصلة بها. - وضع تصور مبائي للاستمارة: قامت الباحثة

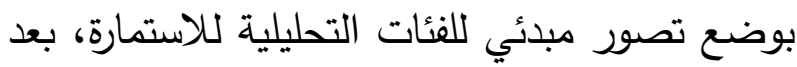
الاطلاع على الاستمارات الخاصة بتحليل المضمون فى الدراسات السابقة ذات الصلة بنفس الموضوع، وقامت الباحثة بعرض الاستمارة على مجموعة من الاساتذة المحكمين، للتعديل أو الحذف أو الإضافة على الوحدات بما يتناسب مع مجريات الدراسة

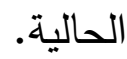

\section{- تحديد المادة التى سيتم تطبيق الاستمارة} عليها: حددت الباحثة المادة التى سيتم تطبيق الاستمارة عليها والخروج منها بمدى توفر أدوات وآليات التفاعل فى الصفحات الإخبارية، بالثبكات

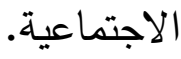
- وحدة التسجيل: اعتمدت الدراسة على وحدة التسجيل الكيفي والكمى، لأدوات التفاعلية بالمواقع

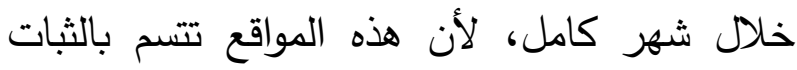
النسبي إلى حد كبير، ولا يتم تغيير أو إضافة لان عناصر الا على فترات متباعدة. - تحديد فئة التحليل: حددت الباحثة فئات التحليل طبقا لأبعاد "كاري هييتر" الست للتفاعلية، وتم تعديل بعض الفئات التحليلية لمواكبة التطورات

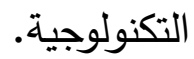


شبكات التواصل الاجتماعى كمواقع إعلام تفاعلي يتصف التفاعل الذى يحدث عبر وسائل الإعلام

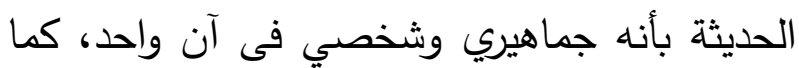

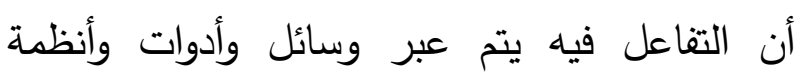

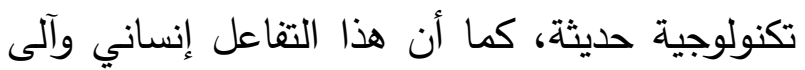
فى آن واحد، فهو تفاعل بين الأفراد (إنسان) ، وتفاعل بين الفرد والآلة

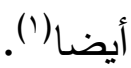
ويذكر رضا عبد الواجد أمين(؟)، أن المواقع الاجتماعية بمختلف أشكالها "منتديات ومدونات وغرف الحوار والدردشة ومجموعات الأخبار والقوائم البريدية وشبكات التعارف من فيس بوك

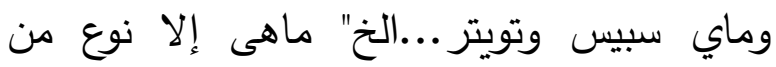
المجتمعات الافتراضية التى تقوم على التفاعل التقافي والاجتماعي، وتبادل الأفكار والآراء عبر لترم

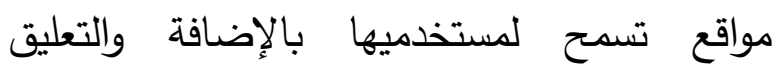
والمشاركة النشطة أثناء التجول، ويمكن إدراج

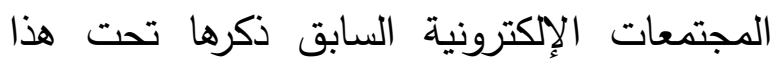
وشبكات التواصل الاجتماعي تقدم الخدمات التى من شأنها تدعيم التواصل، والتفاعل بين أعضاء

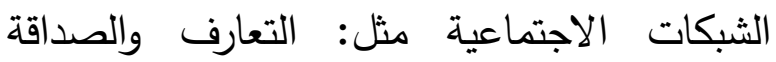
والمراسلة والمحادثة الفورية وإنشاء مجموعات

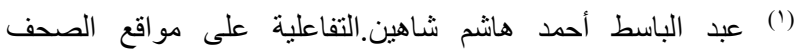

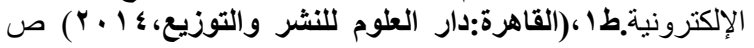
(r) رضا عبد الواجد أمين. حدود التفاعل الاجتماعي فى المجتمعات

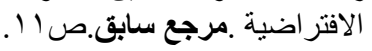

فئة، مندرجة أسفل كل بعد من الأبعاد الستة

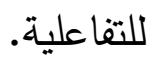

\section{حدود الدراسة}

$$
\text { تمثلت حدود هذه الدراسة فيما يلى: }
$$

- مدود موضوعية: تمثلت فى دراسة التفاعلية كمنتج وعملية و سماتها، وأدواتها، وأبعادها، وآلياتها على الصفحات الإخبارية بالثبكات الاجتماعية عينة

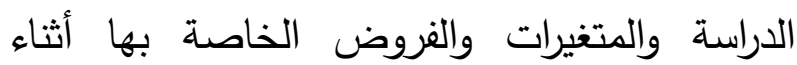


- - حدود زمنية: وهى دراسة أبعاد التفاعلية وأدواتها

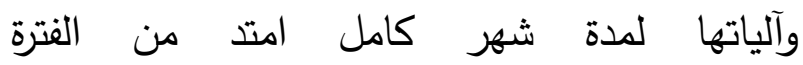

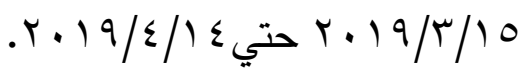
متغيرات الدراسة

تتقسم متغيرات الدراسة الحالية إلى:

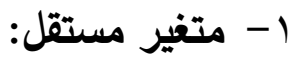

وهو سبب حدوث ظاهرة الدراسة، وهو التفاعلية كمنتج بالصفحات الإخبارية بالثبكات الاجتماعية، وقامت الباحثة بقياس هذا المتغير من خلال: - أبعاد التفاعلية الستة كما حددتها "كاري هييتر"، وتمت إضافة بعض العناصر، وحذف أخري بما تناسب مع موضوع الدراسة. - - نوع المواقع ( شبكات اجتماعية). ץ- متفير تابع : وهو المتغير المراد ملاحظته نتيجة تأثير المتغير المستقل به وهو: - مستوى التفاعل أثناء الاحداث الهامة (التفاعلية

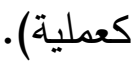


أن (r) $(r+1)$ Tantawy \& Julie B.Wiest

السرعة في تلقي المعلومات ونشرها، هي أهم ما ميز المواقع الاجتماعية أثناء الاحداث الهامة، وتعرف اتصالات الأزمة بأنها "كافة الأنشطة الاعة التهاء

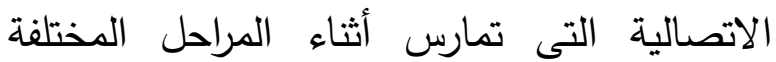
للأزمة بغض النظر عن الوسائل والمضامين المستخدمة فيها، بما فى ذلك أنشطة العلاقات العامة والأدوار الاتصالية التى تقوم بها المنظمات أثناء مراحل الأزمة، وكذلك الأنشطة الاتصالية

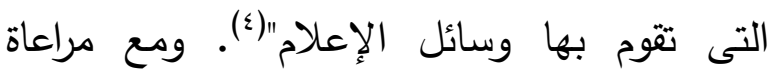

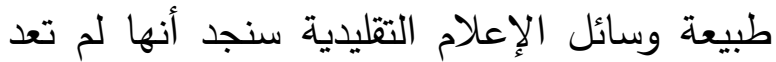
قادرة على التعامل مع الأزمات الطارئة بشكل

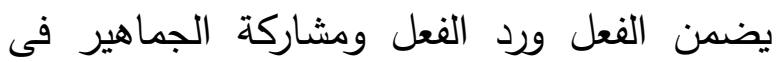
صنع المحتوى ومراسلة الوسيلة فى آن واحد ومحدود بكل أنواع القوالب الإخبارية والمعلوماتية. التفاعلية بالثبكات الاجتماعية كمنتج وعملية تقوم الدراسة التحليلية الكيفية والكمية التالية برصد

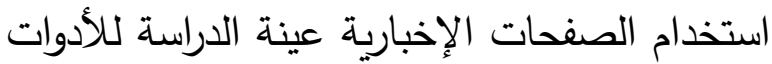
التفاعلية المتاحة على شبكة الإنترنت فى الفترة من

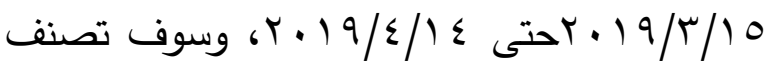
الباحثة أدوات الاتصال والتفاعل وفقا لأبعاد Heeter

(3) Nahed El Tantawy \& Julie B.Wiest. Social Media in The Egyptian Revolution.op.cit.pp.1218.

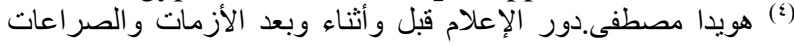

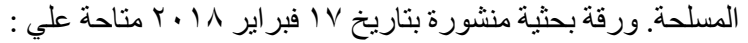

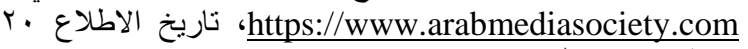

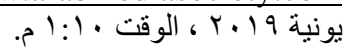

اهتمام وصفحات للأفراد والمؤسسات المشاركة فى الأحداث والمناسبات ومشاركة الوسائط مع الآخرين كالصور والفيديو والبرمجيات(1).

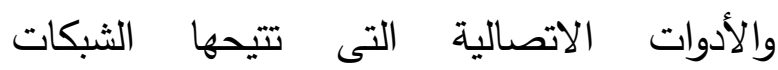
الاجتماعية هى أدوات تفاعلية تستخدم بهدف الانف

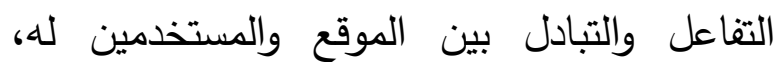
وتهدف بالأساس إلى جذب الجمهور إلى التعامل مع المواقع الاجتماعية وجعل القاعدة عريضة لئة بالجماهير المتفاعلة. حيث أن هذه المواقع تستمد الاجمد قوتها من تفاعل المستخدمين أنفسهم فيما بينهم.

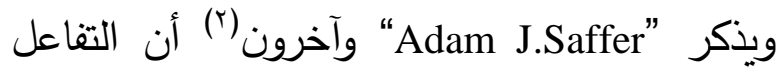
على المواقع الاجتماعية يمكن أن يكون تفاعلاً

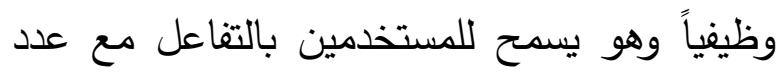

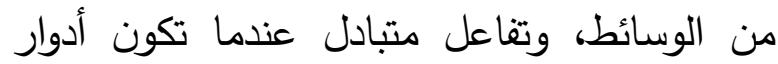
المستخدمين قابلة للتبادل، والمتفاعلون يستجييون لبعضهم البعض. الإعلام التفاعلي أثناء الأزمات

يلعب الإعلام التفاعلي أثناء الازمات دورا هاما فى الإعى الأمات إدارة الأزمة أو الحدث إتصاليا، حيث أن الإعلام

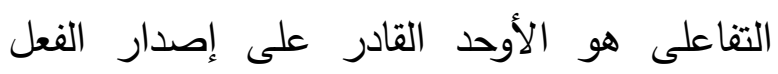

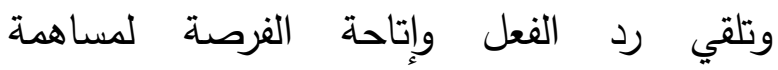
المستخدمين فى وقت محدد جدا تحدده طبيعة

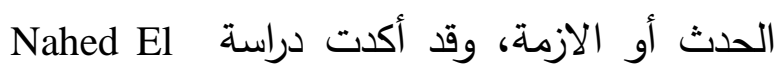

(1) رامي حسين حسني الثر افي. دور الإعلام التفاعلي فى تثكيل الثقافة

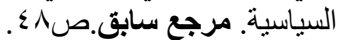

(2) Adam J.Saffer, Erich J.Sommerfeldt,Maureen Taylor. The effects of organizational Twitter interactivity on organization-public relationships.public relations review 39(2013) p.214. 
اتجاه الإتاحة للمستخدمين للتفاعل باللغة التى يبغونها. وتتفق هذه النتيجة مع دراسة أحمد عادل

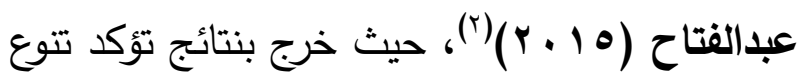
اللغات المستخدمة فى الموضوعات أو التعليقات أو الرسائل، وأشار أيضا إلى أن المستخدمين يميلون إلى استخدام (العامية-العامية المبتذلة) بنسبة

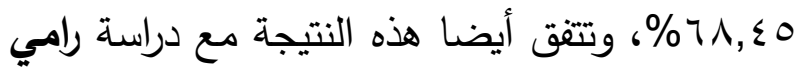
حسين الثرافي (r ا • r)(r)، التى جاء بها أن هنالك تتوعاً واضحاً فى استخدام اللغات بالنسبة لعينة دراسته؛ حيث حصل استخدام اللغة العربية فقط على

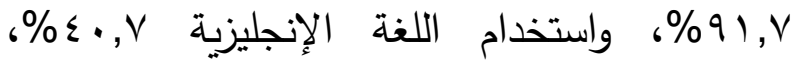
واستخدام اللغتين معا على ع, r \%\%. ץ- استخدام الوسائط المتعددة الفائقة
البعد الأول: الأدوات التى تحقق تعدد الخيارات كيغيا

وكميا Complexity of Choice Available من أجل تحقيق هذا البعد للتفاعلية على الصفحات الاخبارية بالمواقع الاجتماعية لابد من توافر الأدوات التى تحقق تعدد الخيارات من: تعدد اللغات المستخدمة، استخدام الوسائط المتعددة الفائقة، استخدام محركات البحث، خدمات مساعدة،

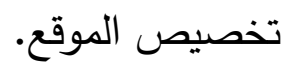
1- تعدد اللغات المستخدمة:

ومن تحليل صفحتى BBC News بالعربية و بالعربية على موقعى الفيس بوك وتويتر France 24 يتضح لدينا أن اللغة الوحيدة المقدمة على هذه الصفحات هى اللغة العربية ويبدو هذا منطقيا حيث أنها صفحات موجهة للجمهور العربي بشكل أساسي وخاص. وقد اتفقت هذه النتيجة إلى حد كبير مع

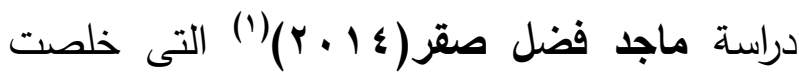
إلى أن جميع المواقع عينة الدراسة أهملت تعدد اللغات، حيث لم يدعم أى موقع من مواقع الدراسة

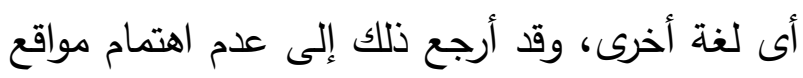
الدراسة بالجمهور الخارجي غير الناطق باللغة العربية. وبتحليل استخدام الجمهور وجد أنه غير مقيد باستخدام اللغة العربية فى التعليقات، فهنالك أيضاً تعليقات باللغة الانجليزية والفرنسية والـ Franco Arabic . وهذا يؤكد أن العملية التفاعلية سارت فى الى (1) ماجد فضل صقر حبيب. التفاعلية في المواقع الإكترونية للصحف

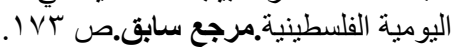


جدول رقم (1) الوسائط المتعددة الفائقة بصفحتي BBC بالعربية وFrance24 بالعربية كيفياً

\begin{tabular}{|c|c|c|c|c|c|c|c|c|c|c|c|c|c|c|c|c|c|c|}
\hline \multirow{2}{*}{\multicolumn{2}{|c|}{ المجموع }} & \multirow{2}{*}{\multicolumn{2}{|c|}{ فلاش }} & \multirow{2}{*}{\multicolumn{2}{|c|}{ فيديو }} & \multirow{2}{*}{\multicolumn{2}{|c|}{ صوت }} & \multirow{2}{*}{\multicolumn{2}{|c|}{ رسوم }} & \multirow{2}{*}{\multicolumn{2}{|c|}{ صور }} & \multicolumn{6}{|c|}{ نص متشعب } & الوبائط \\
\hline & & & & & & & & & & & & \multicolumn{2}{|c|}{ وسيط } & \multicolumn{2}{|c|}{ خارجي } & \multicolumn{2}{|c|}{ داخلي } & \\
\hline$\%$ & ك & $\%$ & ك & $\%$ & ك5 & $\%$ & ك5 & $\%$ & ك5 & $\%$ & ك5 & $\%$ & ك5 & $\%$ & 5) & $\%$ & ك5 & الصفحة \\
\hline $\begin{array}{c}r v, \\
0\end{array}$ & 94 & . & . & $1 \ldots$ & ו & . & . & . & . & $1 \ldots$ & M & . & . & $1 \ldots$ & M & . & . & $\begin{array}{c}\text { BBC } \\
\text { Arabic } \\
(\mathbf{f} / \mathbf{t})\end{array}$ \\
\hline $\begin{array}{c}\text { rv, } \\
0\end{array}$ & 94 & . & . & $1 \ldots$ & ו & . & . & . & . & $1 \ldots$ & ו & . & . & $1 \ldots$ & ו & . & . & $\begin{array}{l}\text { France } \\
24(f / t)\end{array}$ \\
\hline vo & 117 & . & . & $1 \ldots$ & $9 r$ & . & . & . & . & $1 \ldots$ & Tr & . & . & $1 \ldots$ & Tr & . & . & المجموع \\
\hline
\end{tabular}

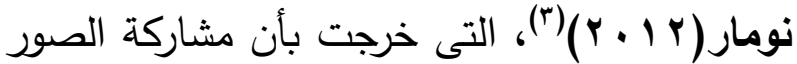

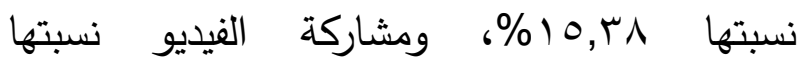

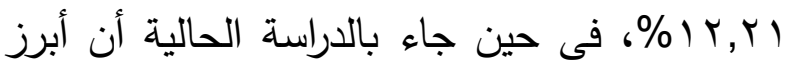
الوسائط المتعددة التى تعتمد عليها الثبكات عينة الدراسة الفيديو والصور بنسبة ...1\%.ويدل هذا على أن العملية التفاعلية لازال بها بعض المحدودية

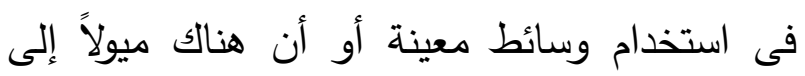
الاستغناء عن ملفات الصوت والفلاش التى لم تعد جذابة مقابلة بالفيديو والصور والنصوص المتشعبة.
ومن بيانات التحليل الكيفي نجد أن صفحتي BBC Arabic المتعددة الفائقة بنسبة \&o\%، ماعدا الروابط الفائقة

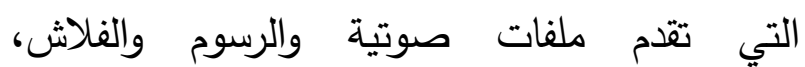

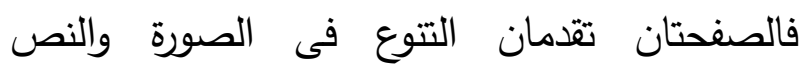
مجتمعين. وتتفق نتيجة الدراسة مع دراسة أحمد

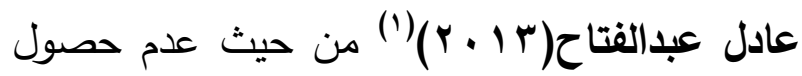
فئة الصوت على أي تكرارات على الإطلاق، بينما

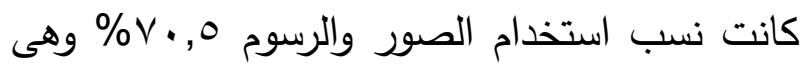

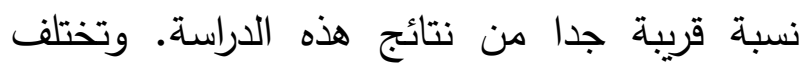

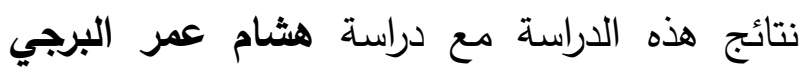

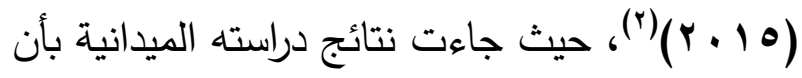

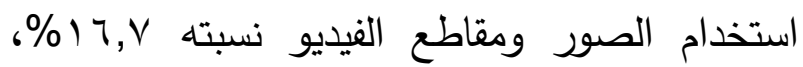

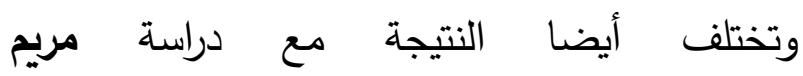

\footnotetext{
(1) أحمد عادل عبدالفتاح. التفاعلية بالمواقع الإلكترونية الصحفية

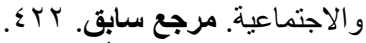

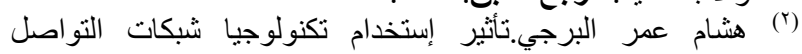

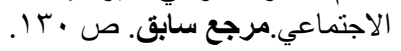


جدول (r) الوسائط المتعددة الفائقة بـ BBC بالعربية بالفيس بوك كمياً

\begin{tabular}{|c|c|c|c|c|c|c|c|c|c|c|}
\hline \multirow{2}{*}{\multicolumn{2}{|c|}{ فيديو }} & \multirow{2}{*}{\multicolumn{2}{|c|}{ صور }} & \multicolumn{6}{|c|}{ نص متشعب } & \multirow[b]{3}{*}{ قضية } \\
\hline & & & & \multicolumn{2}{|c|}{ وسيط } & \multicolumn{2}{|c|}{ خارجي } & \multicolumn{2}{|c|}{ داخلي } & \\
\hline$\%$ & ك & $\%$ & ك & $\%$ & ك5 & $\%$ & 5 & $\%$ & ك5 & \\
\hline$\varepsilon$. & it & 7. & rv & - & . & or & rt & $\cdot$ & $\cdot$ & الأحداث بالجزائر \\
\hline 0 . & 10 & אוז" & YI & . & . & צr t & 11 & . & . & الأحداث بالسودان \\
\hline 1. & r & $7, r$ & $\varepsilon$ & - & . & ir & 7 & . & . & حريق نوتر دام \\
\hline $1 \ldots$ & r. & $1 \ldots$ & $4 r$ & - & · & $1 \ldots$ & 0. & - & $\cdot$ & المجموع \\
\hline
\end{tabular}

جدول (r) الوسائط المتعددة الفائقة بـ France 24 بالعربية بالفيس بوك كمياً

\begin{tabular}{|c|c|c|c|c|c|c|c|c|c|c|}
\hline \multirow{2}{*}{\multicolumn{2}{|c|}{ فيديو }} & \multirow{2}{*}{\multicolumn{2}{|c|}{ صور }} & \multicolumn{6}{|c|}{ نص متشعب } & \multirow[b]{3}{*}{ قضية } \\
\hline & & & & \multicolumn{2}{|c|}{ وسيط } & \multicolumn{2}{|c|}{ خارجي } & \multicolumn{2}{|c|}{ داخلي } & \\
\hline$\%$ & 5 & $\%$ & 5 & $\%$ & ك & $\%$ & ك) & $\%$ & ك & \\
\hline$\leqslant 0,0$ & 1. & 07 & سז & • & - & 09 & $r \leq$ & • & - & الأحداث بالجزائر \\
\hline 0. & 11 & rq & rr & • & · & rq & ir & $\cdot$ & . & الأحداث بالسودان \\
\hline$\varepsilon, 0$ & 1 & 0 & r & - & . & it & 0 & . & - & حريق نوتر دام \\
\hline $1 \ldots$ & rt & $1 \ldots$ & 09 & . & . & $1 \ldots$ & $\sum 1$ & . & . & المجموع \\
\hline
\end{tabular}

جذول (ع ) الوسائط المتعددة الفائقة بـ BBC News بالعربية بتويتر كمياً

\begin{tabular}{|c|c|c|c|c|c|c|c|c|c|c|}
\hline \multirow{2}{*}{\multicolumn{2}{|c|}{ فيديو }} & \multirow{2}{*}{\multicolumn{2}{|c|}{ صور }} & \multicolumn{6}{|c|}{ نص متشعب } & 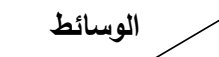 \\
\hline & & & & \multicolumn{2}{|c|}{ وسيط } & \multicolumn{2}{|c|}{ خارجي } & \multicolumn{2}{|c|}{ داخلي } & \\
\hline$\%$ & ك5 & $\%$ & ك & $\%$ & ك5 & $\%$ & ك) & $\%$ & ك5 & ضية \\
\hline$\leq 0$ & 11 & $0 \leqslant, \Gamma$ & بر & - & $\cdot$ & or, $\varepsilon$ & M & • & · & الأحداث بالجزائر \\
\hline$\varepsilon r, 0$ & IV & $r o, v$ & ro & · & $\cdot$ & $r q, r$ & iv & - & . & الأحداث بالسودان \\
\hline$M, 0$ & 0 & 1. & V & - & $\cdot$ & $I V, r$ & 1. & • & . & حريق نوتر دام \\
\hline $1 \ldots$ & $\varepsilon$. & $1 \ldots$ & $v \cdot$ & . & $\cdot$ & $1 \cdots$ & $0 \wedge$ & - & $\cdot$ & المجموع \\
\hline
\end{tabular}

جدول (o) الوسائط المتعددة الفائقة بـ 24 France بالعربية بتويتر كمياً

\begin{tabular}{|c|c|c|c|c|c|c|c|c|c|c|}
\hline \multirow{2}{*}{\multicolumn{2}{|c|}{ فيديو }} & \multirow{2}{*}{\multicolumn{2}{|c|}{ صور }} & \multicolumn{6}{|c|}{ نص متشعب } & \multirow[b]{3}{*}{ ضية } \\
\hline & & & & \multicolumn{2}{|c|}{ وسيط } & \multicolumn{2}{|c|}{ خارجي } & \multicolumn{2}{|c|}{ داخلي } & \\
\hline$\%$ & ك5 & $\%$ & كs & $\%$ & كs & $\%$ & 5) & $\%$ & ك5 & \\
\hline$T r, 0$ & ro & $00, \varepsilon$ & $\varepsilon 1$ & . & $\cdot$ & $\varepsilon 9,1$ & rq & • & • & الاحداث بالجزائر \\
\hline$r \wedge, \uparrow$ & 17 & $r q, V$ & rr & . & $\cdot$ & $r V, r$ & 17 & . & $\cdot$ & الاحداث بالسودان \\
\hline$\wedge, q$ & 0 & $1 \leqslant, 9$ & 11 & - & . & $r T, V$ & $1 \leq$ & . & . & حريق نوتر دام \\
\hline $1 \ldots$ & 07 & $1 \ldots$ & $V \varepsilon$ & . & · & $1 \ldots$ & 09 & . & . & المجموع \\
\hline
\end{tabular}




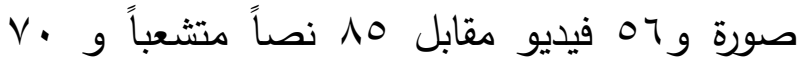
صورة و ، ع فيديو بصفحة BBC News بالعربية. ومن هنا ومن خلال التحليل الكمي السابق ظهرت التفاعلية كعملية تدار من قبل القائمين على الصفحات فى استخدام الوسائط المتعددة الفائقة بشكل مكثف أثناء عرض القضايا الثلاثة محل الدراسة، حيث أن الصفحتين كثفتا استخدام المنتج في تقديم أدوات النصوص الفائقة المتعددة أثناء تقديم أخبارها ومعلوماتها. ومن الملاحظ أنه كلما توافرت أدوات الوسائط المتعددة الفائقة التفاعلية فى موقعى الفيس بوك وتويتر ارتفع نشاط العملية التفاعلية من قبل القائمين على الموقعين في المقابل.
وبالتحليل الكمي للصفحتين على شبكة الفيس بوك وتويتر وجد أنه بالنسبة للفيس بوك هنالك تقوق لصفحة BBC بالعربية فى عدد الأخبار المقدمة مقارنة بـFrance 24 بالعربية، وتتوعت الأدوات التى تحقق تعدد الخيارات بنسبة ، 0 نصاً متشعب خارجياً كان أغلبها يتناول الأحداث بالجزائر فى حين كان العدد ب France 24 بالعربية إ نصاً كان اغلبها يتناول الأحداث فى الجزائر أيضاً، و وج صورة مقابلة مع وه صورة في France24 بالعربية تتاول معظمها أيضا الأحداث بالجزائر ، و · ب فيديو مقابلة

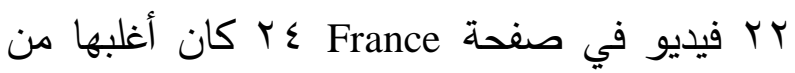
نصيب الأحداث بالسودان. أما بالنسبة لتويتر فهناك تفوق فى استخدام الأدوات التقاعلية بصفحة France 24بالعربية حيث أنها قدمت

$$
\text { r- استخدام محركات البحث }
$$

\begin{tabular}{|c|c|c|c|c|c|c|c|c|}
\hline \multirow{2}{*}{\multicolumn{2}{|c|}{ المجموع }} & \multirow{2}{*}{\multicolumn{2}{|c|}{ بحث خارجي }} & \multicolumn{4}{|c|}{ البحث الداخلي } & \multirow[b]{3}{*}{ ففحة } \\
\hline & & & & \multicolumn{2}{|c|}{ بحث متقدم } & \multicolumn{2}{|c|}{ بحث سريع } & \\
\hline$\%$ & ك) & $\%$ & 5) & $\%$ & ك) & $\%$ & 5) & \\
\hline 77,7 & Tr & . & - & $1 \ldots$ & r & $1 \ldots$ & 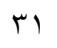 & BBC Arabic $(f / t)$ \\
\hline 77,7 & Tr & $\cdot$ & - & $1 \ldots$ & ו & $1 \ldots$ & M & France $24(\mathrm{f} / \mathrm{t})$ \\
\hline 77,7 & ITE & . & . & $1 \ldots$ & $T r$ & $1 \ldots$ & Tr & المجموع \\
\hline
\end{tabular}

الشخصي المسجل به أو أرقام هواتفهم أو بمجرد كتابة الاسم فقط، أو فيديوهات وقنوات، أما أداة البحث الخارجي فهى غير مدعومة وبذلك تحصل محركات البحث على نسبة 7,7\% \% على مقياس الأبعاد التفاعلية. وتتفق هذه النتيجة مع دراسة أحمد
ومن بيانات التحليل كيفياً فقط -لأنه توجد آلية للحصر كمياً- وجد أن الصفحات الإخبارية بالشبكات الاجتماعية عينة الدراسة توفر أداة البحث الداخلي سواء عن صفحات أو مجموعات أو موضوعات أو اشخاص، سواء بعناوين بريدهم 
من أن آلية التعليق المباشر علي الموضوعات والقتوات حصلت علي المركز الأول، تلاها فئة

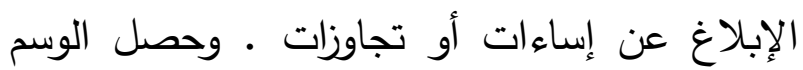

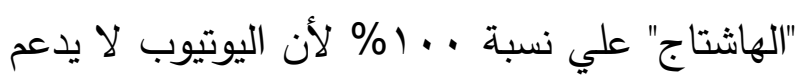

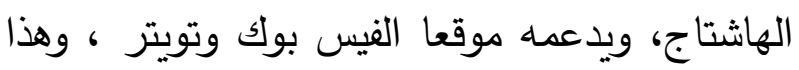

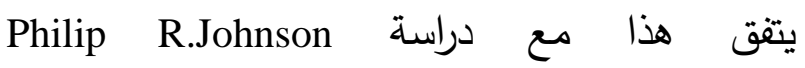

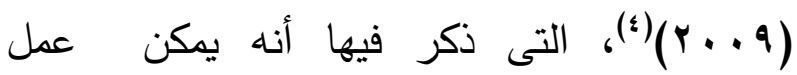
الهاشتاج على تويتر باستخدام نسقreplies @ وذكر أن الهاشتاج يعتبر من أكثر الروابط استخداما

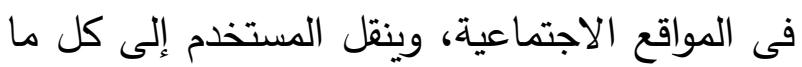
كتب حول موضوع الهاشتاج بمجرد الضغط عليه. وبالتحليل الكمي للصفحتين على الفيس بوك وجد

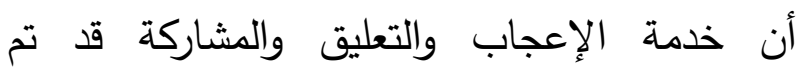
استخدامهما بنسبة ...\% حيث أن الحصيلة بصفحة BBC News بالعربية تمثلت فى ov ملصقاً

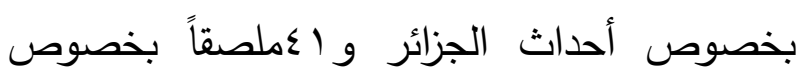
احداث السودان و 0 ملصقات بخصوص حريق نوتر دام. أما بالنسبة لصفحة France 24 بالعربية

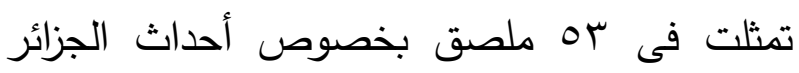
و TV ملصق بخصوص أحداث السودان و و 7 ملصقات تتاولت حريق نوتردام. وجاء موقع تويتر بنفس النتيجة حيث بتحليل وحصر التغريدات عن الثلاث قضايا عينة الدراسة وجد أن خدمة الإعجاب

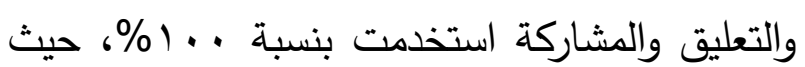
كان عدد التغريدات بصفحة BBC News بالعربية

${ }^{(4)}$ Philip R.Johnson. Uses and Gratifications of Twitter.op.cit. p.8.

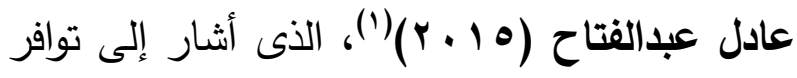
إمكانية البحث عن المعلومات وطرقها المختلفة بموقع الفيس بوك، مما يعزز سهولة الوصول إلى

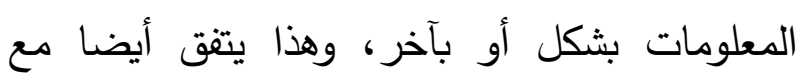

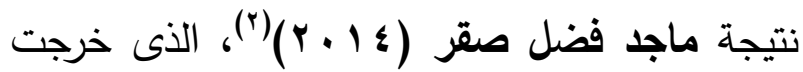
دراسته بغياب البحث الخارجي عن مواقع الدراسة

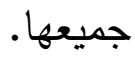

ومن هنا نجد أن المنتج التفاعلى المتمثل فى أداه محركات البحث سوف يوفر عملية تفاعلية ناجحة عند حاجة المستخدم للبحث عن خبر أو معلومة، وبالتالى هنالك ضمان لوجود تفاعل دائم ومستمر

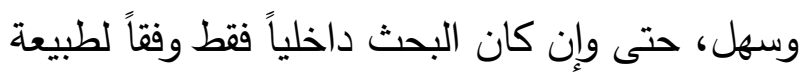

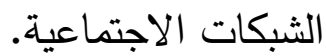
ع - - - خدمات مساعدة

تسعى الثبكات الاجتماعية عينة الدراسة إلى عرض الاهتمامات المفضلة لدى كل مستخدم فى حال سمح الاجل

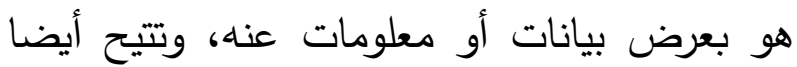

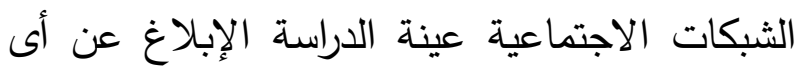
محتوى أو شخص غير مرغوب ومنعه من الوصول بنسبة ...1\%. وتتيح الشبكات الاجتماعية عينة الدراسة أدوات التعليق والإعجاب للموضوعات والمنشورات ومقاطع الفيديو بنسبة ...1\%، ويتقق

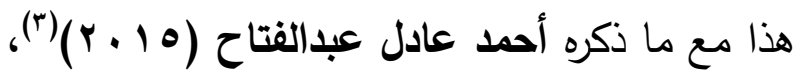
(1) أحمد عادل عبدالفتاح.التفاعلية بالمواقع الإكترونية الصحفية

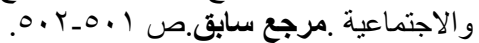

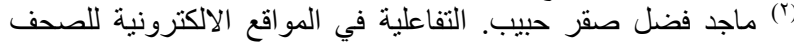

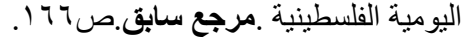

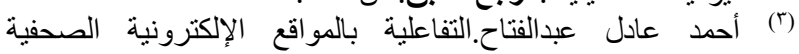
و الاجتماعية.مرجع سابق.ص م م. م. 
بوك، قد تكون بيئة مريحة لجلب الخطاب السياسي

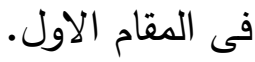

وبذلك نخلص الى أنه فيما يخص أدوات الخدمات المساعدة فإن العلاقة عكسية بين المنتج والعملية فالمنتج قليل في الفيس بوك ولكن العملية التفاعلية في حالة ازدياد، والمنتج كثير في تويتر ولكن العملية التفاعلية قليلة جدا، وبذلك تتأثر العملية التفاعلية بحجم الهنتج التفاعلى على الثبكات الاجتماعية عينة الدراسة. 0- تخصيص الموقع تدعم الصفحات الإخبارية الأدوات التفاعلية التى

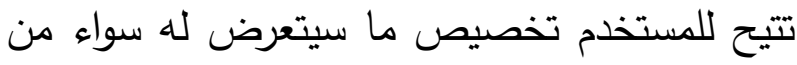
مضمون صفحات أو قنوات أو أشخاص، وله أيضا أن يخصص رداً أو مضموناً لشخص معين بنسبة أولات

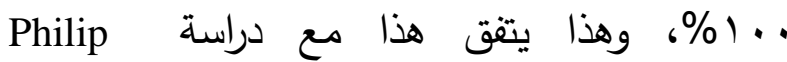
R.Johnson إجراء محادثات عامة بالرد على مستخدم آخر

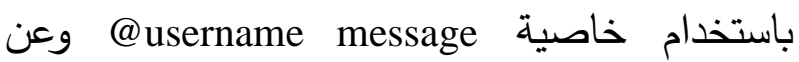
طريقها يتم إرسال الرد إلى مستخدم معين.وإن كان تخصيص الموقع لا يمكن حصره كميا إلا أنها أحدى الحى أهم الخصائص التى تميز الثبكات الاجتماعية عن غيرها من المواقع حيث يمكن للمستخدم إيقاف الإثعارات من شخص معين أو ملصق معين أو الو الو إخفاؤها إذا تطلب الأمر .

${ }^{(3)}$ Philip R.Johnson."Uses and Gratifications of Twitter".op.cit. P.8.
بالنسبة للشأن الجزائري ع^ تغريدة، والثأن السودانى r O تغريدة، وحريق نوتر دام ·r تغريدة، وتمثلت

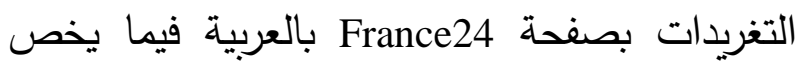
الثأن الجزائري ب VA تغريدة، وفيما يخص الثأن

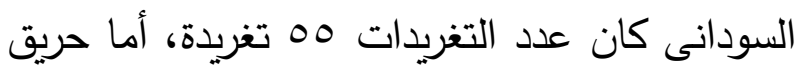
كنيسة نوتر دام فكان عدد التغريدات ^^ تغريدة.

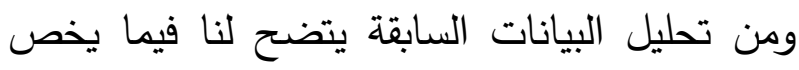

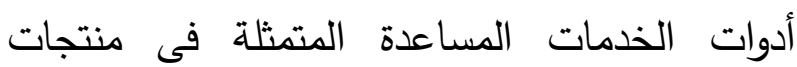
تفاعلية هامة مثل الإعجاب والتعليق بالرأى أو الششاركة ...الخ، كان هناك علاقة عكسية على الإلى

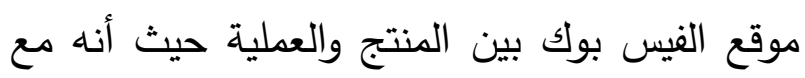
قلة عدد الملصقات زادت أعداد الاعجاب والتعليق والمشاركة ، أما في موقع تويتر كانت العلاقة عكسية متمثلة فى أنه مع زيادة التغريدات قلت أعداد

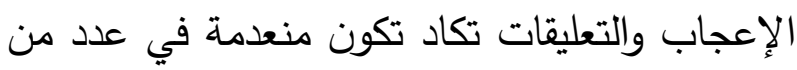
التغريدات والمشاركة، وتتفق أيضا مع نتيجة دراسة

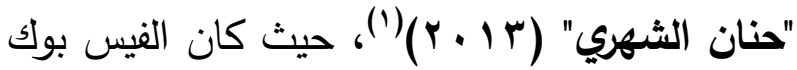
أكثر استخداما من تويتز بين أفراد عينتها وقد أرجعت ذلك الي أن تويتر قد يكون ملائماً أكثر للراغبين بالمناقشات الجادة عادة أما الفيس بوك فهون نظام حياة شامل فيه الجد والمرح والتجمعات وغيرها من الخصائص. واتقق هذا أيضا مع تحليل المحتوى

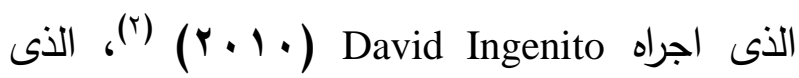
وجد فيه أن المجتمعات على الإنترنت مثل الفيس

(1) حنان بنت شعشوع الثهري.أثر استخدام شبكات التو اصل الالكترونية

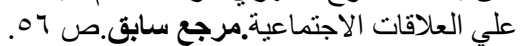

(2)Ingenito,D.".Democaracyin21st Century"op.cit.p.45. 
وفى نهاية تحليل الأدوات الاتصالية التى تحقق المستخدم وتبقى بهذا ثنائية الاتجاه تضمن الفعل ورد

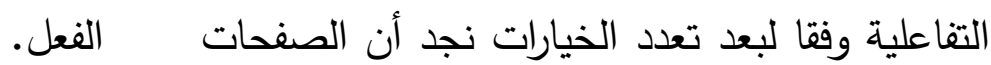
الإخبارية عينة التحليل تسعى جاهدة إلى توفير كل البعد الثاني: الأدوات التى تحقق تقليل الجهد الذي

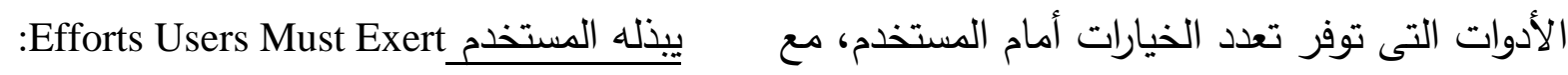
بعض الاستثناءات الطفيفة. وبذلك نجد ان العملية الـ البناء العام للموقع التفاعلية تسير فى اتجاه التجدد والمرونة وتحكم جدول رقم (V) الأدوات التى تحقق تقليل الجها الذى يبذله المستخدم كيفياً

\begin{tabular}{|c|c|c|c|c|c|c|c|c|c|c|}
\hline \multicolumn{2}{|c|}{ المجموع } & \multicolumn{2}{|c|}{ صفحات ذات } & \multicolumn{2}{|c|}{ التلميحات } & \multicolumn{2}{|c|}{ تخصيص التصنيف } & \multicolumn{2}{|c|}{ التصنيف } & البناء العام \\
\hline$\%$ & ك5 & $\%$ & ك & $\%$ & ك & $\%$ & ك5 & $\%$ & ك & الصفحات \\
\hline vo & 94 & $1 \ldots$ & M & . & . & $1 \ldots$ & M & $1 \ldots$ & M & BBC Arabic (f/t) \\
\hline vo & $q 4$ & $1 \ldots$ & ו & - & - & $1 \ldots$ & ו & $1 \ldots$ & ו (1) & France $24(f / t)$ \\
\hline vo & 111 & $1 \ldots$ & 94 & . & · & $1 \cdots$ & 94 & $1 \ldots$ & Tr & المجموع \\
\hline
\end{tabular}

الصفحة الشخصية للمستخدم بشكل تلقائي ودائم. ومن بيانات التحليل وجد أن موقع الفيس بوك يدعم التحديث بشكل تلقائي لكل مستخدم دون الحاجة إلى لئ

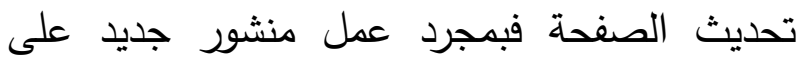

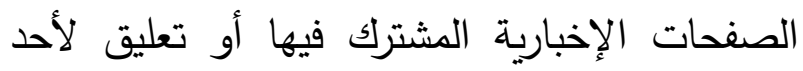
الأصدقاء يصل إلى المستخدم كل جديد عن طريق التبيهات "الإشعارات" على صفحته الخاصة، وموقع التويتر يدعم التحديث بشكل تلقائي وسريع بدون الحاجة إلى تحديث الصفحة بنسبة ... \%)، كما أن الصفحات الإخبارية تدعم عرض أحدث الرسائل الواردة مع الإشعار اليها، وهذا يختلف مع دراسة

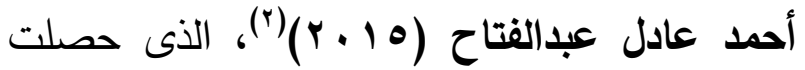
آلية عرض أحدث الرسائل والموضوعات لديه على و الاحتماعية نفس عبدالفتاح. التفاعلية بالمواقع الإكترونية الصحفية
ومن تحليل الصفحات الإخبارية وجد أنها جميعها تدعم إتاحة وتوفير روابط للموضوعات والأخبار Philip R.Johnson المختلفة وهذا يتفق مع دراسة ونويرة

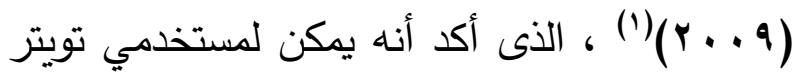

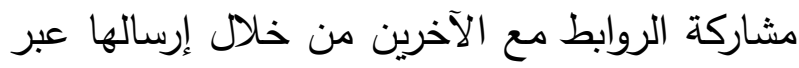
تويتر مع رسالة موجزة، وتتشر أيضا المنظمات والهيئات المستخدمة لتويتر مثل صحيفة نيويورك تايمز على سبيل المثال التحديثات بشكل مستمر مع لمع وضع وصلات إلى أحدث المقالات الإخبارية، ولكن لا تدعم الشبكات عينة الدراسة التلميحات فى القوائم.

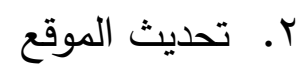

المواقع الاجتماعية بمجرد الاشتراك فى مجموعاتها

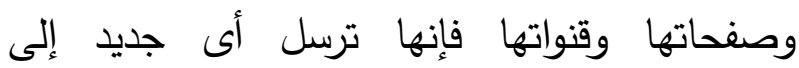

\footnotetext{
${ }^{(1)}$ Philip R.Johnson. Uses and Gratifications of Twitter.op.cit P.8.
} 
المواقع على شبكة الإنترنت فى الوقت الراهن، ولا تحتاج لمتابعة من قبل القائمين على الموقع، ولا لهالي تتطلب أى جهد بشري لمتابعته، إلا أن هذا البعد

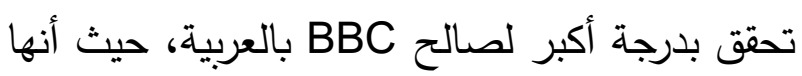

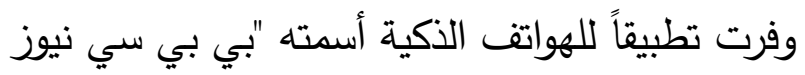
عربي" للأخبار المحلية والعالمية

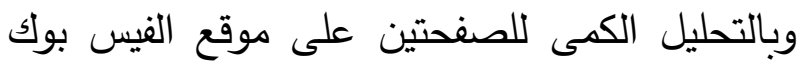
وجد أنه تمثل عدد المعبين لصفحة 24 France

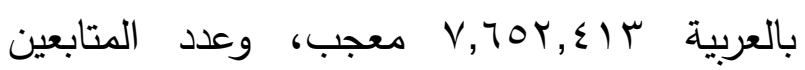
للصفحة

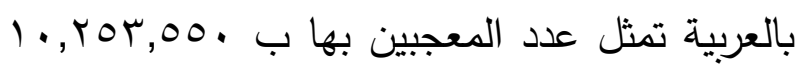

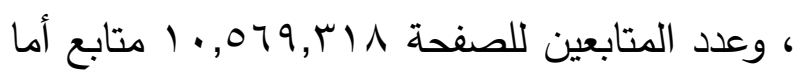

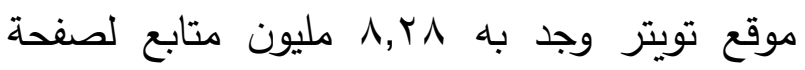
France24 BBC

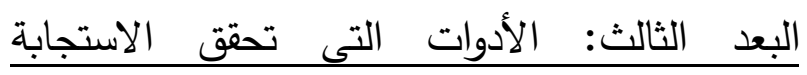

لمستخدم Responsiveness to the user ومن بيانات التحليل وجد أن أدوات الاستجابة للمستخدمين من قبل القائمين على الصفحتين لم تحصل سوى على نسبة 7,77\%، فالإجابة على

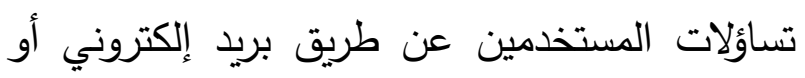
رقم هاتف مباشر لم تكن من أولويات ال BBC

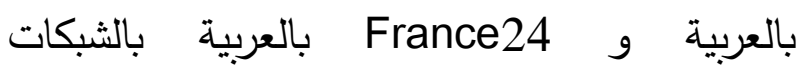

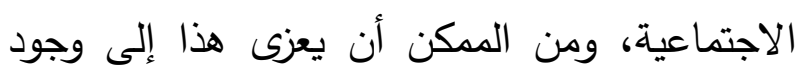

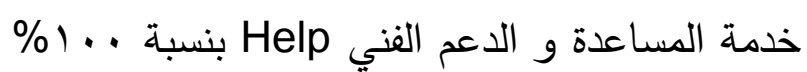
فى الثبكتين فعلى سبيل المثال موقع تويتر يتيح
\% \%,v 9,9\%. ولاحظت الباحثة من دلالات الأرقام الواردة تساوى الصفحات الإخبارية بالشبكات الاجتماعية فى آلية تحديث الموقع وطرقها المختلفة وهذا يدل بلدال على تثابهها فى آليات التفاعلية والخدمات المقدمة ولحة

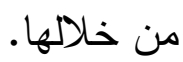
r. تقديم المعلومات حسب الطلب يستطيع المستخدم عن طريق هذه الأداة اختيار نوعية المعلومات والموضوعات التى يرغب فى في لهن

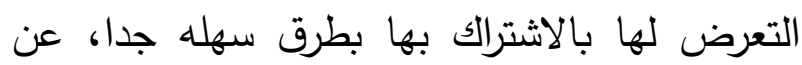

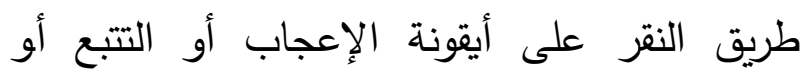

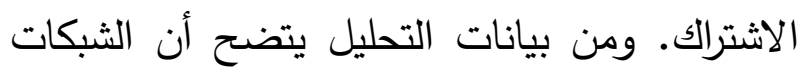

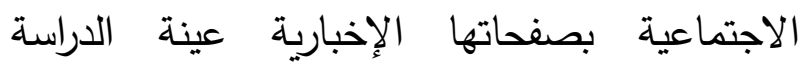
حريصة على تقديم المعلومات حسب الطلب بنسبة .... ومجموعات وقنوات محددة تبعا لميول المستخدم،

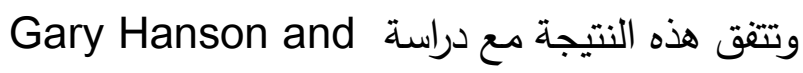
Haridakis الاشتراك فى التتبيهات حسب طلب المستخدم لإشعاره بكل ما يستجد فى موضوع أو حدث معين على الصفحة الإخبارية.

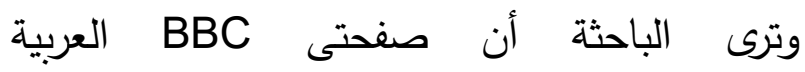
وFrance24 بالعربية توفر كل سبل تقديم المعلومات حسب الطلب بشكل متساوٍ، لأنها أدوات تعتمد على تقنيات برمجية أصبحت متاحة فى كل

(1) Gary Hanson and Paul Haridakis. YouTube Users Watching and Sharing the News.op.cit.online. 


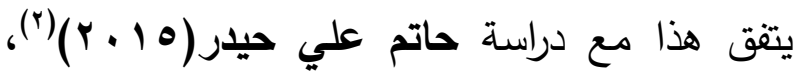
الذى أكد أن المستخدمين يمكنهم تبادل الاتصال والمحادثة من خلال غرفة الدردشة المتاحة شمال حائط المستخدم، وهذا النوع من التفاعل يتطابق مع معنه

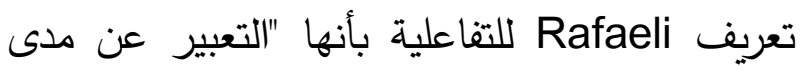
ترابط سلسلة التبادلات الاتصالية والرسائل، أى قدرة الوسيلة على نقل رد فعل المستقبل إلى المرسل. يتقق هذا أيضا مع دراسة Philip R.Johnson

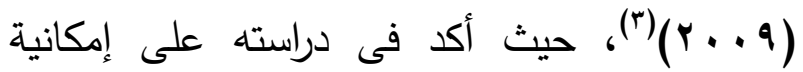
إجراء محادثات خاصة مع الآخرين عبر رسائل مباشرة، ويتم إرسالها بتنسيق username message التى يطلع عليها بشكل خاص من قبل المرسل والمتلقى فقط. البعد الخامس: أدوات تحقق سهولة إضافة المعلومات:

ومن تحليل البيانات كيفيا وجد أن صفحة BBC بالعربية و صفحة France 24 بالعربية على موقع الفيس بوك تدعمان بعض الأدوات التى تحقق سهولة

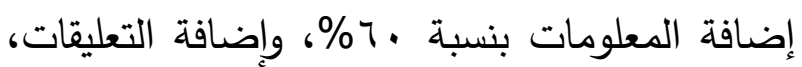

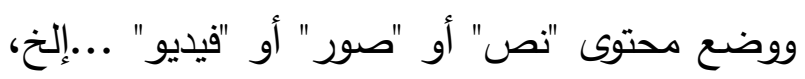

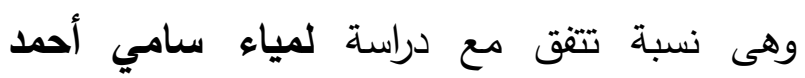

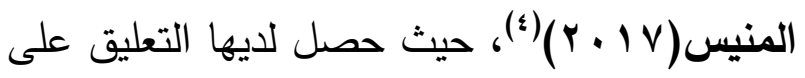
نسبة ... (\%)،لا يدعم المشاركة فى المحتوى بحيث

(r) حاتم علي حيدر مقبل الصالحي. استخدام تكنولوجيا الاتصال التفاعلي.

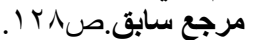

(3) Philip R.Johnson.Uses and Gratifications of Twitter.op.cit.p.8.

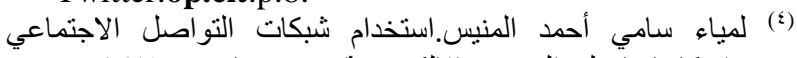

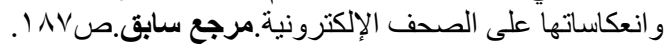

مركزاً كاملاً للمساعدة والدعم الفني والإجابة الفورية للأسئلة الأكثر شيوعا. وتتوافر خدمة الإبلاغ عن

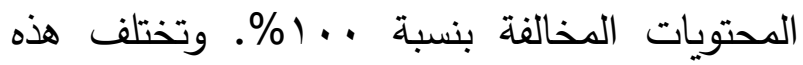

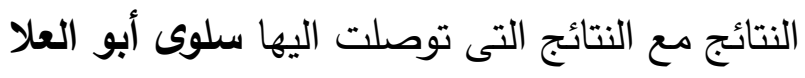

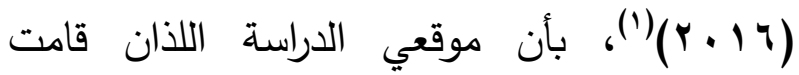
ببحثها لم يحرصا على وجود الأدوات التفاعلية

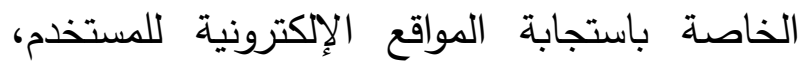
حيث كان نسبة هذه الأدوات فى موقعي الدراسة

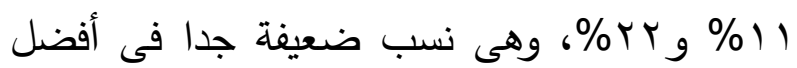

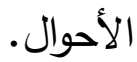

وترى الباحثة أن السبب فى عدم دعم صفحتى بالعربية و France 24 بالعربية بالثبكات الاجتماعية الفيس بوك وتويتر لبعض أدوات

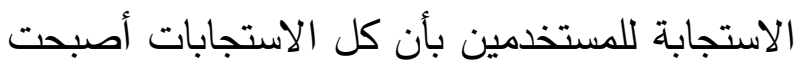

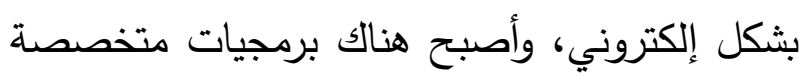
للتجاوب مع المستخدمين فى حلول مشاكلهم والرد على استفساراتهم ولم يعد هناك داع للتدخل البشري. البعد الرابع: أدوات تسهيل الاتصال الشخصي: ومن تحليل البيانات وجد أن الصفحتين الإخباريتين

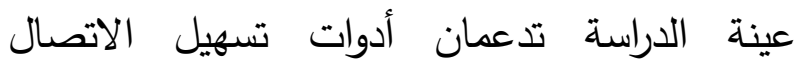

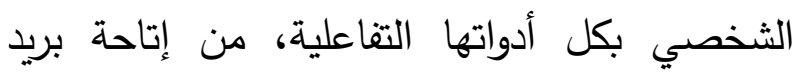

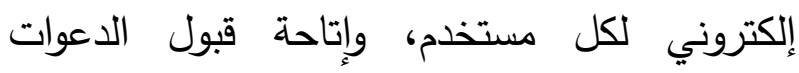
للمناسبات المختلفة، ووضع إشارة ، ولكن لم يدعما وضع ملصقات ومقاطع وتدوين مصغر . (1) سلوي أحمد محمد أبو العلا.أساليب نحقيق التفاعلية في تصميم المواقع مرجع 
الشخصية للجميع، ويسمح بإبداء الإعجاب كرد فعل وإعادة تغريد للمحتوى. وهذا يتفق مع ما جاء فى دراسة هثام البرجي

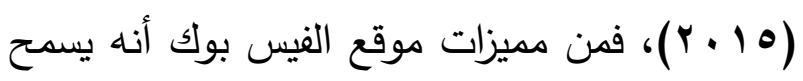
بالتحكم فيمن يمكنه رؤية المعلومات الشخصية

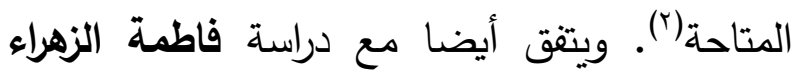

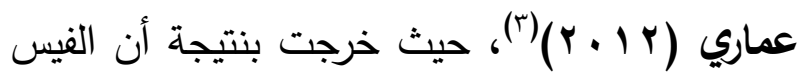

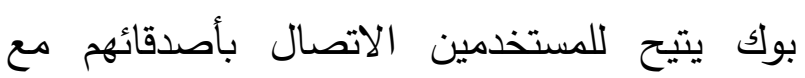

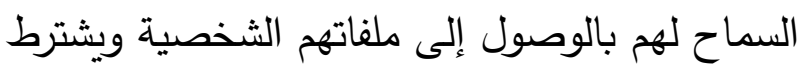
موقع الفيس بوك التسجيل من أجل التصفح والتعليق

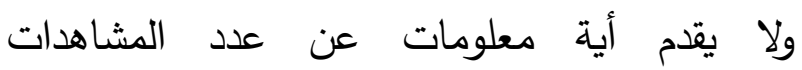
للموضوع، ولكن يتيح الفرصة لعرض ردود الأفعال.

\section{الخاتمة ونتائج الدراسة وتوصياتها}

\section{أولا: خاتمة الدراسة}

حاولت الباحثة من خلال هذه الدراسة معرفة أدوات

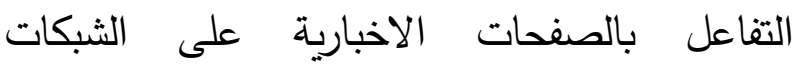

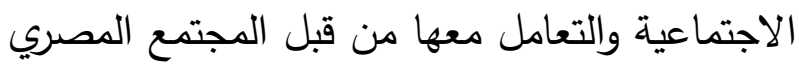

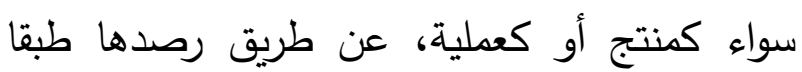

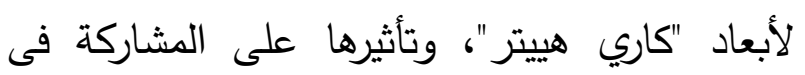
بعض القضايا المحيطة بالمجتمع المصري. وذلك من خلال تحقيق الهدف الرئيسي للدراسة

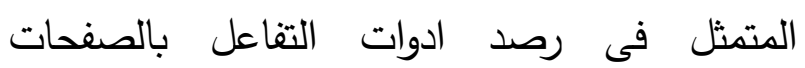

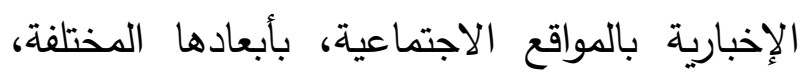

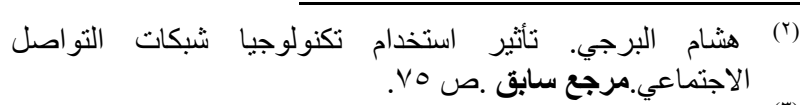

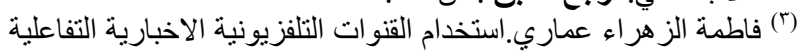

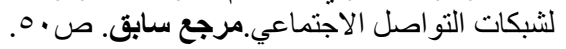

لا يمكن لمستخدم تغيير محتوى مشاركة مستخدم

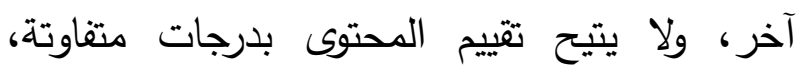
فالموقع يدعم الإعجاب فقط بالموضوع، وهذا لا لاني

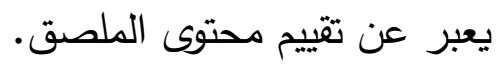
أما الصفحتان الإخباريتان بموقع التويتر فإنهما تدعمان بدورهما آليات إضافة التعليقات، ومشاركتها

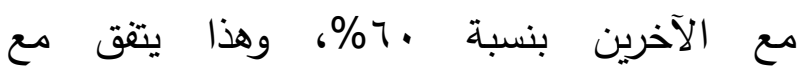

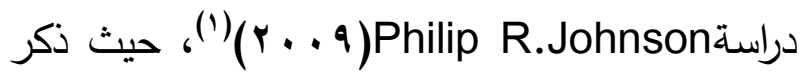
أنه يمكن للمستخدمين الفرديين مشاركة الروابط مع الآخرين من خلال إرسالها إلى تويتر مع رسالة موجزة. ولا يدعم المشاركة فى المحتوى، ولا يتيح التثييم للمحتوى بدرجات متفاوتة بل يتيح الإعجاب فقط وهذا لا يجعل التقييم بنسب معلومة.

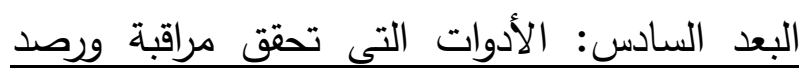
استخدامات المتلقي للوسيلة ومن تحليل بيانات الصفحتين الإخباريتين على الصى موقعي الفيس بوك وتويتر وجد أن أدوات هذا البعد تتحقق بنسبة ، ج\% ميث تشترط BBC بالعربية و و France24

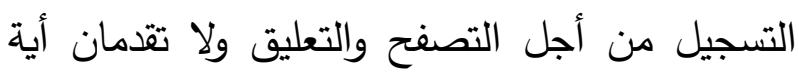
معلومات عن عدد المشاهدات للموضوع، ولكن تتيح الفرصة لعرض ردود الأفعال. أما موقع التويتر فإنه

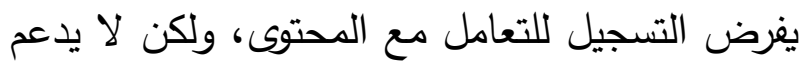
تقديم معلومات عن عدد الزيارات، ولا يقدم معلومات عن الشخص إلا بعد موافقته على عرض بياناته

(1) Philip R.Johnson. Uses and Gratifications of Twitter.op.cit.P.8. 
وتوصيف أدواتها من منظور مقياس التفاعلية وذات فائدة للتعامل مع الاخبار والمعلومات بشتى الوظيفية، وبإستخدام منهج المسح الثامل لمفردات نواحيها.

\section{ثانيا: النتائج:}

تناول هذا البحث الأدوات الاتصالية التى توفرها

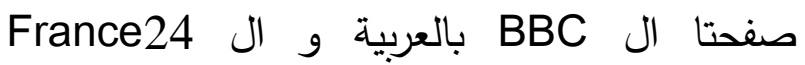
بالعربية بالثبكات الاجتماعية (فيس بوك- تويتر) من خلال الأبعاد الستة التى حددتها كاري هيتر للتفاعلية، وبناءاً عليه تم تحليل التفاعلية كمنتج وعملية من خلال تصنيف وتحليل الأدوات التى تمكن المستخدمين الأعضاء من التفاعل أثناء الاستخدام والتعامل مع المواقع طبقا لكل بعد من

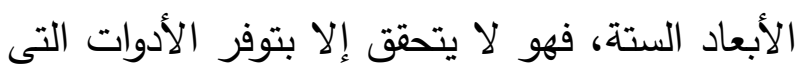

تدعمه وتحققه، وخلص البحث إلى الآتى:-

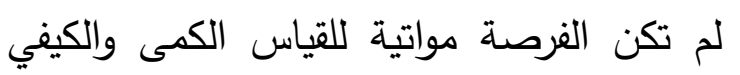
فى آن واحد لكل الأبعاد، حيث أنه كان هنالك أبعاد قيست بشكل كيفي وكمى وأبعاد قيست كيفيا فقط لصعوبة إيجاد آلية لحصر الأدوات التفاعلية وحجم ولعماد التعامل معها من قبل الجمهور كميا، وإن كان ذلك لا يؤثر على سهولة استنباط ومتابعة التفاعلية كمنتج

$$
\text { وعملية فى هذه الدراسة. }
$$

موقع الفيس بوك هو من أكثر مواقع الثبكات الاجتماعية حرصا على توفير وتحديث الأدوات الاتصالية المقدمة على صفحاته للمستخدمين، وهذا يفسر كونه صاحب شهرة عالية بين الأوساط

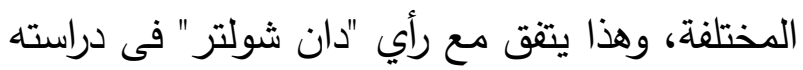
حيث أوضح أن الأساس الاجتماعى الذى تقوم عليه العينة، وباستخدام أداة تحليل المضمون. وقد توصلت الدراسة إلى مجموعة من النتائج المتعلقة بالدراسة التحليلية بناء على التحليل الكيفي

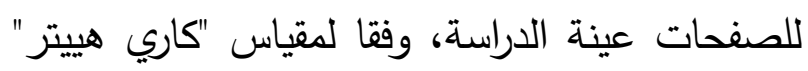

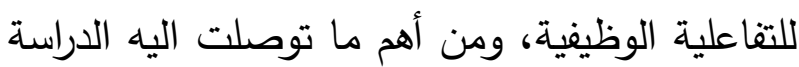
أن الصفحات الاخبارية بالشبكات الاجتماعية مازالت ينقصها شوطاً كبيراً لتوفير كل الأدوات التفاعلية، على الأقل فلم توظف هذه الصفحات أدوات تفاعلية تحقق الاستجابة للجماهير بشكل كافي. ودلت النسب العالية لبعد "تقليل الجهد الذى يبذله المستخدم" أن

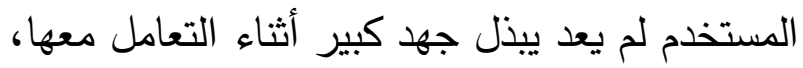
مع وجود أدوات تفاعلية مثل التصنيف، وتخصيص لبدل التصنيف...الخ، واعطت النتائج مؤشر اخر يدل على المتابعة والآنية بفضل عنصر التحديث بشكل

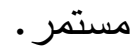

ودلت النتائج على انه لازالت هناك فجوة بين القائمين على الصفحات الاخبارية بالمواقع الاجتماعية، والجماهير المستخدمة لها، وذلك بسبب عدم تقديم أدوات تسهل الاتصال الشخصي بشكل

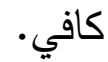

ومن هنا نجد هذه الدراسة هامة لتوسيع مجال البحث

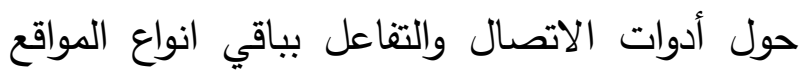
على شبكة الانترنت من منظور المنتج والعملية؛ لتحسين أدائها وتطوير بنيتها وجعلها أكثر انتشارا 
المواضع بموقع تويتر-مثل أدوات الخدمات

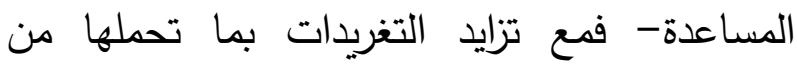
أدوات تفاعلية قلت العملية التفاعلية، أما الفيس بوك على الرغم من قلة عدد الملصقات معابلة بتويتر إلا أن العملية التفاعلية تتم بشكل أكبر. أحداث الجزائر كانت الأكثر تداولا فى فترة

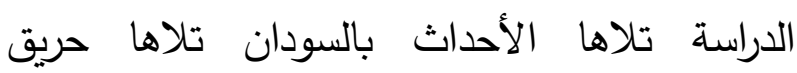
نوتردام، وكان التقوق لموقع تويتر نظرا لاعتماده

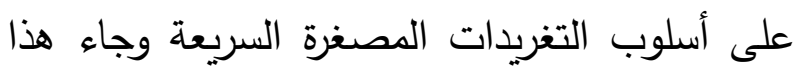
على حساب التعليقات والاعجاب والمشاركة من قبل

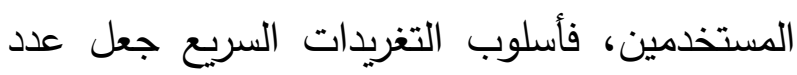
التعليقات والإعجاب والمشاركات محدود مقابلة مع التعات الكعاب نفس الصفحات ونفس القضايا على الفيس بوك. بناء على النتيجة السابقة يتضح أن السرعة في نقل الأخبار والتغريدات يتضمن ميزة وعيباً فى نفس النس الوقت حيث أن الميزة تكمن فى السرعة والفورية

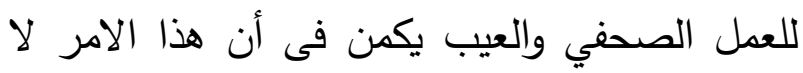
يتيح الفرصة للتفاعلية من قبل المستخدمين. خلصت الباحثة إلى أن الصفحات الإخبارية على الصى

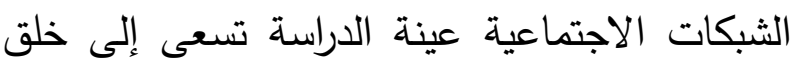

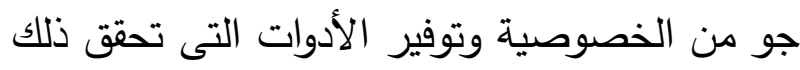

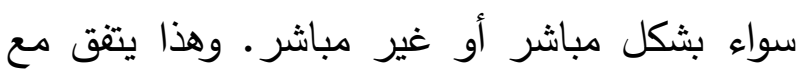

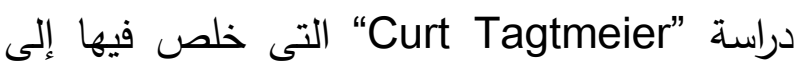

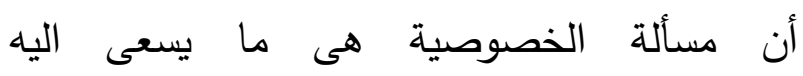
المستخذمون بشكل أساسي وتمثل أهمية قصوى لئية بالنسبة لمستخدمي موقع الفيس بوك، أما بالنسبة
التفاعلية يفسر بوضوح سبب كونه-موقع الفيس بوك- موقع التواصل الاجتماعي صاحب الثهرة الأعلى؛ فقد تحول اليوم إلى المرافق الأيائم لمحترفي

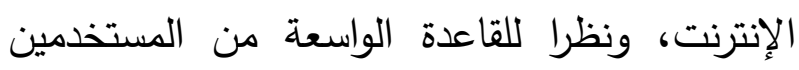

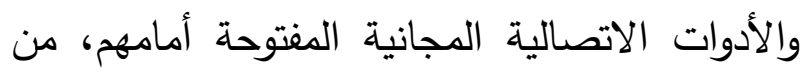

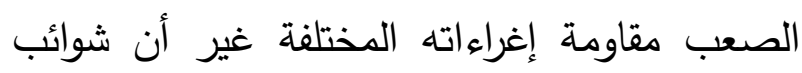
الموقع تجعله أبعد من أن يكون ناجحا من الناحية التنظيمية (1). موقع " تويتر" يميل إلى احتلال المراكز الأولى الكى

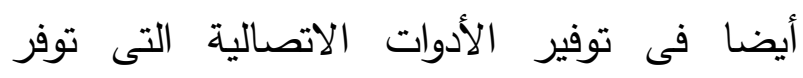

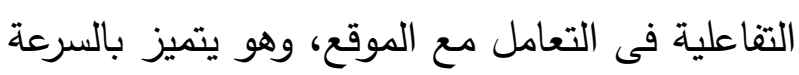
فى التحديث والتفاعل، فالموقع يدعم بالأساس التساس التدوين الدصغر والتعليقات السريعة حول التغريدة.

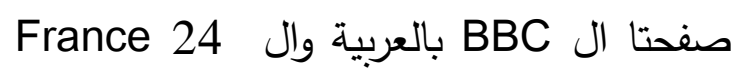
بالعربية على موقع الفيس بوك بهما مرونة أكثر في الكية العملية التفاعلية حيث تتوافر الأدوات الاتصالية طبقا للأبعاد الستة لكاري هييتر بنسبة عالية مقارنة بالصفحتين بموقع التويتر وإن كان الفارق ضئيلاً.

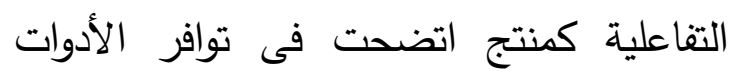
التفاعلية على الصفحات الإخبارية، أما التفاعلية

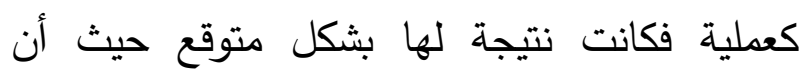

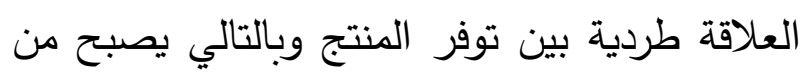

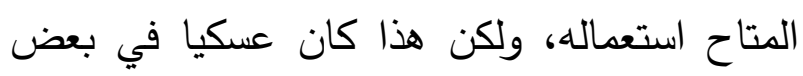

(1) دان شولتز. مقدمة عن فاعلية فيس بوك/ ترجمة رين مطر، V، يناير

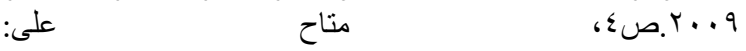
https://www.scribd.com/doc/10739213/DigActive-sIntro-to-Facebook-Activism-Arabic 
الفئات المراد الوصول اليها في المجتمعات وخاصة أثناء الأحداث الهامة.

على الباحثين الاهتمام بتوسيع نطاق البحث

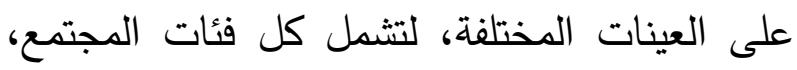

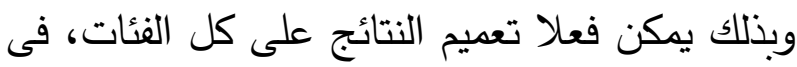
حالة فهم طبيعتهم، وبذلك يمكن فهم هوية كل

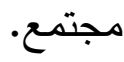

• الإكثار من الدراسات التى تهدف إلى شرح

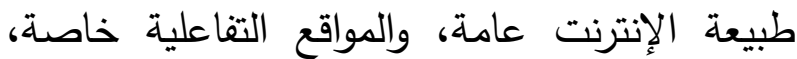
والاهتمام بنشرها على نطاق واسع، لرفع مستوى النقري الوعي بها، وثقافة التعامل معها.

الاهتمام بدراسة مخاطر التفاعلية على شبكة الإنترنت، والاهتمام بنشر نتائج الدراسات، على لـى لته

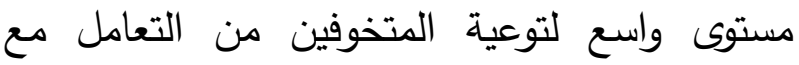
المواقع التفاعلية، وإرشادهم إلى حسن التصرف وكيفية التصرف فى حالة الوقوع فى أخطاء أو الو التعرض للمضايقات والمشاكل، وبذلك طمأنة الفئات المتخوفة من التعامل مع مالمواقع التعاعلية، وتثجيعهم على التعامل مع لغة العصر .

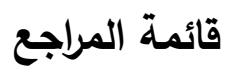

أولا: قائمة المصادر والمراجع العربية: الرسائل العلمية الغير المنشورة ا ـ أحمد عادل عبدالفتاح محمد. التفاعلية بالمواقع الالكترونية الصحفية والاجتماعية وعلاقتها بمستوي التفاعل الاجتماعي والسياسي لدي الثباب المصري: في إطار نظريتي ثراء الوسيلة والحضور
لمستخدمي موقع "تويتر" فهناك ميل نحو جعل كل

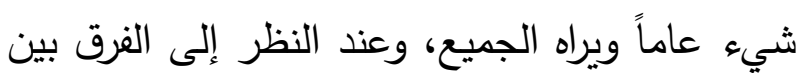
الخدمتين بالموقعين نجد موقع الفيس بوك يتيح إضافة الأصدقاء، وفى الجانب الآخر يمنح تويتر إتباع التغريدات Followers دون الحاجة لإضافة الأصدقاء (')

"Philip Ryan ويتقق هذا مع ما توصل اليه فohnson" فى المقام الأول كمصدر للمعلومات، وليس كوسيلة لتلبية الاحتياجات الاجتماعية، وبالتالي فالمنتج التفاعلى يكون واضحاً وموجوداً ولكن هذا لا يعني الاجئي أن العملية التفاعلية في موقع تويتر تحتل الصدارة مقارنة بالفيس بوك.

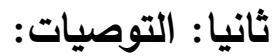

تعرض الباحثة فى نهاية الدراسة، أهم التوصيات

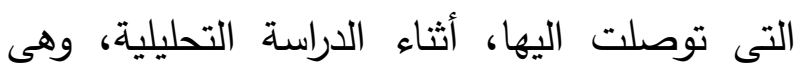

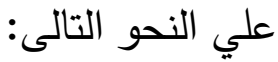
" المرورة تبني المواقع التفاعلية، الأدوار الهامة فى المجتمع، مثل: التتشئة والمسئولية والتوعية الاجتماعية، والسياسية، والثقافية، والدينية، .....الخ. ضرورة اهتمام كل أنواع الصحف ووكالات الأنباء، بالمواقع التفاعلية، واعتبارها منصات مجانية

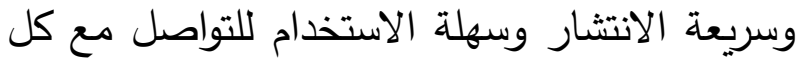

(1) Curt Tagtmeier.Facebook vs. Twitter: Battle of the Social Network Stars, (Illinois: Fremont Puplic Library, 2010),p.3.

(2) Philip R.Johnson. Uses and Gratifications of Twitter.op.cit.P.3. 


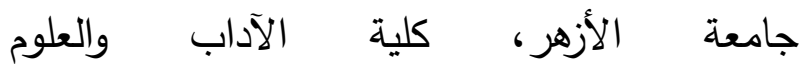

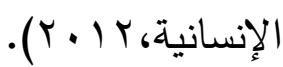
V. سماح عبدالرازق الثهاوي. علاقة التفاعلية باستخدام الثباب للمواقع الموجهة لهم علي شبكة الإنترنت: دراسة ميدانية علي الجمهور والقائم بالاتصال. رسالة ماجستير غير منشورة(جامعة القاهرة: كلية الاعلام،9، . . ب).

A. صابر حسن محمد طر. العلاقة بين الاعتماد علي المواقع الإخبارية الإلكترونية ومستوي المعرفة بالقضايا السياسية اليمنية والعربية لدي الثباب اليمني، رسالة دكتوراه غير منشورة(جامعة القاهرة: كلية الإعلام، ؛ ( . (r). 9. طاهر حسن أبوزيد. دور المواقع الاجتماعية التفاعلية في توجيه الرأي العام الفلسطيني وأثرها علي المشاركة السياسية: دراسة ميدانية، رسالة ماجستير غير منشورة(غزة: جامعة الأزهر: كلية الاقتصاد والعلوم الإدارية، r ( ا ب).

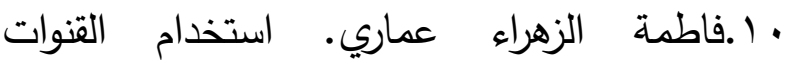
التلفزيونية الاخبارية التفاعلية لشبكات التواصل الاجتماعي: حالة الفيس بوك، رسالة ماجستير غير منشورة(جامعة الجزائر: كلية العلوم السياسية

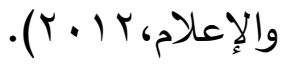
ا ا. ماجد فضل صقر حبيب ـ التفاعلية في المواقع الالكترونية للصحف اليومية الفلسطينية : دراسة تحليلية ،رسالة ماجستير غير منشورة(الجامعة الاسلامية بغزة: كلية الآداب، ع ( ب م).
الاجتماعي/ دراسة تطبيقية دقارنة. رسالة دكتوراه غير منشورة(جامعة المنصورة: كلية التربية

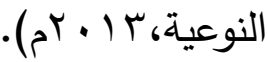
r. أسماء مسعد عبدالمجيد أبو عيطة .الاتصال التفاعلي لدي مستخدمي مواقع الشبكات الاجتماعية في المنطقة العربية ،رسالة دكتوراه غير منشورة (جامعة القاهرة: كلية الاعلام ، 10 ( ب) . r. ثائر محمد تلاحمة. حراسة البوابة الإعلامية والتفاعلية في المواقع الإخبارية الفلسطينية علي شبكة الانترنت. رسالة ماجستير غير منشورة.) جامعة الشرق الاوسط: كلية الاعلام.ب ( . (Y). ع. حاتم علي حيدر مقبل الصالحي. استخدام تكنولوجيا الاتصال التفاعلي في ممارسة أنشطة العلاقات في المنظمات العاملة في اليمن، رسالة ماجستير غير منشورة(جامعة القاهرة: كلية الإعلام، $\cdot(r .10$ 0. حنان ينت شعشوع الشهري. أثر استخدام شبكات التواصل الإلكترونية علي العلاقات الاجتماعية: الفيس بوك وتويتر نموذجا. رسالة ماجستير غير منشورة(جامعة الملك عبدالعزيز: كلية الآداب والعلوم الانسانية، ب ( • ( ). 7. رامي حسين حسني الشرافي. دور الاعلام التفاعلي في تشكيل الثقافة السياسية لدي الثباب الفلسطيني: دراسة ميدانية علي طلبة الجامعات في قطاع غزة. رسالة ماجستير غير منشورة.(غزة: 
7 ا .رحيمة الطيب عيساني، أشكال التفاعلية لدي مستخدمي شبكات التواصل الاجتماعي من الثباب

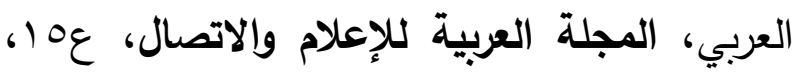

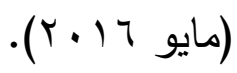

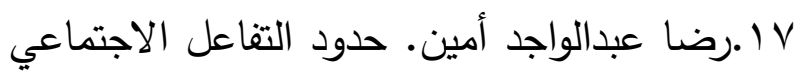
في المجتمعات الافتراضية علي شبكة الإنترنت مؤتمر تقنيات الاتصال والتغير الاجتماعي،

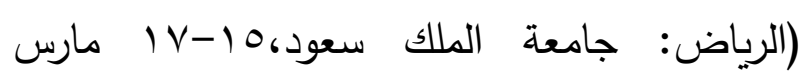
$\cdot(r \cdot .9$

1) .سعيد محمد الغربب النجار. التفاعلية في الصحف العربية على الإنترنت. المؤتمر الدولي

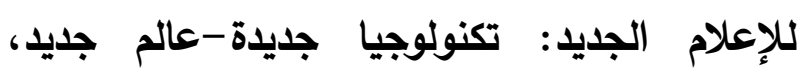

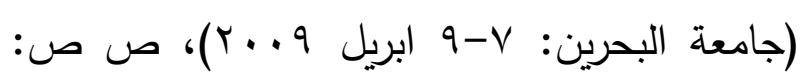

$$
.014-009
$$

9 (.سلوي أبو العلا الثريف. أساليب تحقيق التفاعلية في تصميم المواقع الإككترونية السياحية الرسمية - دراسة تحليلية مقارنة ، المجلة المصرية

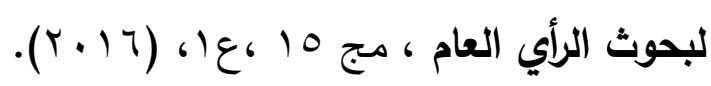
•...عالية أحمد عبد العال. شبكات التواصل الاجتماعي ودورها في تعبئة الحركات الاحتجاجية الجماهير: مؤتمر "مستقبل الإعلام بعد الثورات العربية"،(القاهرة: جامعة الأهرام الكندية - كلية

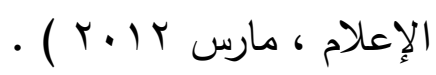
ا. .لمياء سامي أحمد المنيس. استخدام شبكات التواصل الاجتماعي وانعكاساتها علي الصحف الصفي r ا. محمود محمد أحمد. الاتصال التفاعلي لدى مستخدمي صفحات القنوات الإخبارية بمواقع الشبكات الاجتماعية والإشباعات المتحققة منها. رسالة ماجستير غير منشورة،(جامعة المنيا: كلية التربية النوعية، VI V • rم). r ا. مريم نريمان نومار • استخدام مواقع الثبكات الاجتماعية وتأثيره في العلاقات الاجتماعية دراسة عينة من مستخدمي موقع الفيس بوك في الجزائر . رسالة ماجستير غير منشورة(الجزائر : جامعة الحاج لخضر -باتنة، r ( ا ب ). با. نورهان رجب أحمد حسين. تأثير استخدام الثباب المصري لمواقع التواصل الاجتماعي علي مشاركتهم السياسية، رسالة ماجستير غير منشورة، (جامعة القاهرة: كلية الإعلام، IV) (Y). ع ا ـ هشام سعيد فتحي عمر البرجي. تأثير استخدام تكنولوجيا شبكات التواصل الاجتماعي عبر الانترنت على العلاقات الاجتماعية للأسرة المصرية، رسالة ماجستير غير منشورة(جامعة القاهرة: لية الإعلام، 10 (r. (r). الدوريات والمجلات العلمية والمؤتمرات والتقارير 1.حلمي محمود محمد أحمد محسب. قياس تفاعلية المواقع التلفزيونية الإخبارية على الإنترنت: بالتطبيق علي موقعي الجزيرة و CNN. CN المجلة

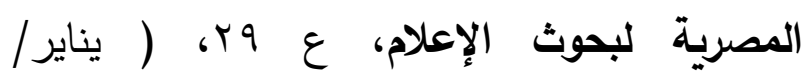

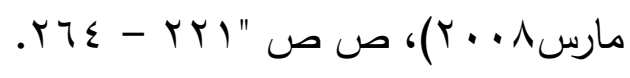


بr.دان شولتز • ترجمة رين مطر • مقدمة عن فاعلية

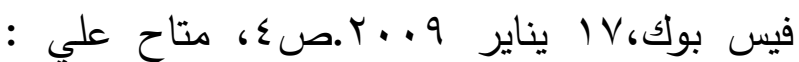
https://www.scribd.com/doc/10739213/DigAct .ive-s-Intro-to-Facebook-Activism-Arabic ؟ ז. هويدا مصطفى. دور الإعلام قبل وأثناء وبعد الأزمات والصرعات المسلحة. ورقة بحثية منشورة

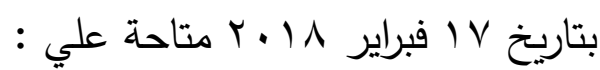
'https://www.arabmediasociety.com

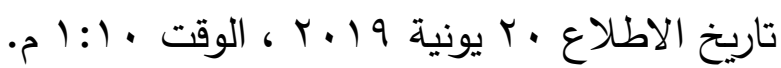
Journal Of Electronic Publlishing" .vol.11,Issue3. Fall2008. Available at: http://dx.doi.org/10.3998/3336451.0011.305. 7. Jens, F.Jense. " Interactivity : Tracking a new concepts in media and communication studies ". Nordicom Review Oxford University vol.(19),no.(1),November2003at :http://www.nordicom.gu.se/common/publpdf/38-jensen.pdf. pp. 185.

8. Kiousis, S.(2001)" Public Trust or Mistrust? Perceptions of Media Credibility in the Information age." Journal of Mass Communication \& Society. 4(4).

9. Nahed El Tantawy \& Julie B.Wiest.Social Media in The Egyptian Revolution:Reconsidering Resource Mobilization Theory. International Journal of Communication 5 (2011).

10.Sundar, S.(1999). Summer) "Exploring Receivers" Criteria for Perception of Print and Online news." Journalism \& Mass Communication Quarterly. 76 (2). pp: 373386.

11. Curt Tagtmeier.Facebook vs. Twitter: Battle of the Social Network Stars, (Illinois: Fremont Puplic Library, 2010).

\section{مو اقع الإنترنت ومقالات منشورة عبر شبكة الإتترنت}

12. Joan M. Reitz. Online Dictionary for Library and Information1 Science.retrieved at http://www.abc-

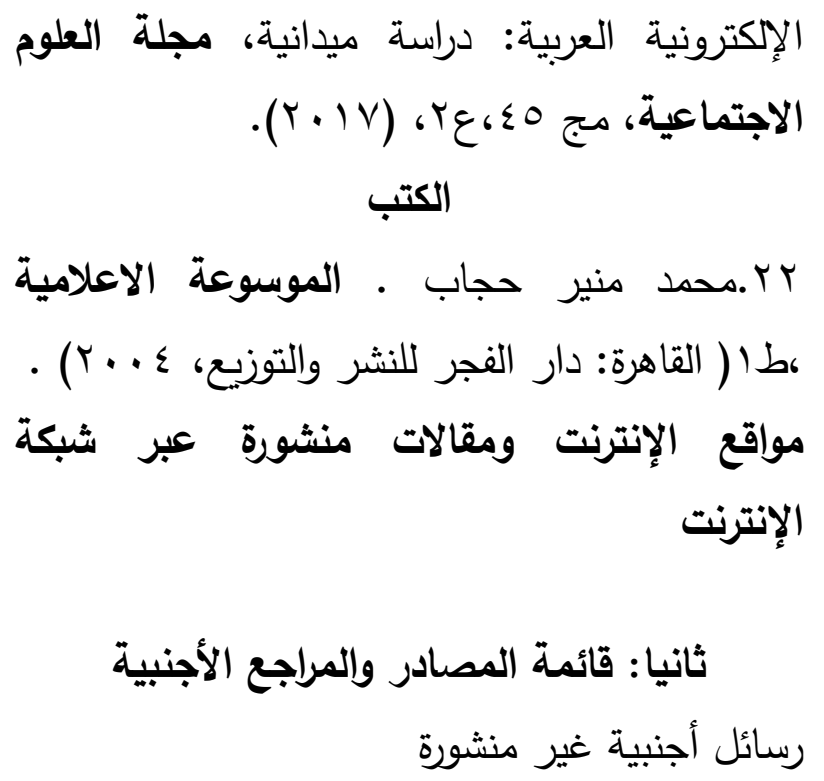

1.Boroughs,B "Social networking websites and voter turnout ". Unpublished M.A (Washington ,Dc : Georgetown University,2010 ).

2.Budak, A."facebook ,Twitter and Barack Obama:New Media and the 2008Presidential Elections".Unpublished M.A.(Washington ,Dc: Georgetown University,2010.

3.Ingenito,D."Democaracyin21st Century :Social Media and Politics-global village or cyber-balkans?" Unpublished M.A.( Los Angeles ,CA:University of Southern California,2010).

$$
\text { الدوريات والمجلات العلمية والمؤتمرات و التقارير }
$$

4. Adam J.Saffer, Erich

J.Sommerfeldt,Maureen Taylor. The effects of organizational Twitter interactivity on organization-public relationships. public relations review 39(2013) p.214.

5.Ancu ,M \& Cozma ,R R ." Myspace Politics :Uses and Gratifications of Befriending Candidates

.In:"journal of Broadcasting \& Electronic Media". Vol.53,No.4,December 2009.pp.567583 .

6.Gary Hanson and Paul Haridakis. YouTube Users Watching and Sharing the News: A Uses and Gratifications Approach."The 
14.Philip R.Johnson.Uses and Gratifications of Twitter: An Examination of User Motives and Satisfaction of Twitter Use.september.2009. available at: https://www.researchgate.net/publication/2289 $\underline{59109}$.
clio.com/ODLIS/searchODLIS.aspx on April $21,2015$.

13. Jennifer Stromer-Galley (2004) Interactivity-as-Product and Interactivity-asProcess, The Information Society, 20:5, 391394, DOI: 10.1080/01972240490508081. 


\title{
Social media communication and interaction tools as a product and process An analytical study on news pages during important events
}

\author{
Dr. Alaa Maher Khafaga \\ Ph.D in Mass Communications from the Department of Mass Communications \\ Faculty of Arts and Humanities - Minia University \\ Dr_alaamaher86@yahoo.com
}

\begin{abstract}
. the importance of this study stems from the fact that it is one of the studies that attempts to understand all the interactive elements contained in social networks and used by news pages through them, and also because it tries to limit all modern interactive tools that these networks have provided to users, and aims in the first place to monitor interactive tools with news pages on networks Social in its various dimensions, describing its tools from the perspective of a functional interactive scale, and knowing the extent to which the Arab public uses these tools during important events.

Based on the foregoing, the research problem was focused on trying to understand interactivity as a product and process during various important events in the Arab region and the extent of their verification in news pages on social networks, by monitoring and analyzing interactive tools on these pages, and knowing the extent to which these pages benefit from modern options, and the new tools that the Internet provides In order to increase interactivity, it sought to uncover the nature of the Arab societies' interaction with events in Algeria and Sudan, and the fire of the Notre Dame Church, through the quantitative and qualitative analysis of the BBC NEWS and FRANCE 24 pages in Arabic on Facebook and Twitter during the period. The accompanying events, which spanned from 15/3/2019 to $14 / 4 / 2019$, due to the relative stability of social networks. The main hypothesis of this study was that "interactivity in the communicative process that takes place through social media news pages is largely available in the event that tools are available that enable interactivity, and an effective user at the same time", it is a feature of the medium and the user together as a product and process.

By applying the "Carey Heeter" scale, including its scale of functional interactivity, and analyzing the content according to the six dimensions of interactivity, the results proved that the events of Algeria were the most widely discussed during the study period, followed by events in Sudan, followed by the fire of the Notre Dame Church. And that the BBC NEWS pages in Arabic and FRANCE 24 in Arabic on Facebook have more flexibility in the interactive process, as the communication tools are available according to the six dimensions of Carrie Heiter at a high rate compared to the two pages on the Twitter site, although the difference is small, and the interaction became clear as a product in the availability of interactive tools on news pages As for the interactivity as a process, it was an expected result of it since the relationship is direct between the availability of the product and the availability of its use
\end{abstract}

key words: "Interactivity"

"News pages"

"Social networks" 